\title{
Nanofiber-based systems intended for diabetes
}

\author{
Hassan Maleki ${ }^{1,6^{*}+}$, Kamyar Khoshnevisan ${ }^{2,3,6^{*+}} \mathbb{C}^{0}$, Sayed Mahmoud Sajjadi-Jazi ${ }^{4,6,8}$, Hadi Baharifar ${ }^{5,6}$, \\ Maryam Doostan ${ }^{1}$, Nazanin Khoshnevisan ${ }^{6}$ and Farshad Sharifi, ${ }^{7,6}$
}

\begin{abstract}
Diabetic mellitus (DM) is the most communal metabolic disease resulting from a defect in insulin secretion, causing hyperglycemia by promoting the progressive destruction of pancreatic $\beta$ cells. This autoimmune disease causes many severe disorders leading to organ failure, lower extremity amputations, and ultimately death. Modern delivery systems e.g., nanofiber (NF)-based systems fabricated by natural and synthetic or both materials to deliver therapeutics agents and cells, could be the harbinger of a new era to obviate DM complications. Such delivery systems can effectively deliver macromolecules (insulin) and small molecules. Besides, NF scaffolds can provide an ideal microenvironment to cell therapy for pancreatic $\beta$ cell transplantation and pancreatic tissue engineering. Numerous studies indicated the potential usage of therapeutics/cells-incorporated NF mats to proliferate/regenerate/remodeling the structural and functional properties of diabetic skin ulcers. Thus, we intended to discuss the aforementioned features of the NF system for DM complications in detail.
\end{abstract}

Keywords: Nanofiber, Diabetic wound, Electrospinning, Scaffold, Wound dressing, Delivery systems, Cell transplantation

\section{Introduction}

Nowadays, diabetes mellitus (DM) acts as a colossal problem and life-threatening disease for humanity health by globally escalating prevalence. DM is recognized by glucose level dysregulation in blood result from defects in insulin secretion by pancreas (type $1 \mathrm{DM}$ ) and/or impair the response of body to insulin (type 2 DM) [1, 2]. In 2019, all over the world, 463 million people suffered from DM, with 4.2 million deaths yearly and it is estimated to strike about 700 million by 2045 [3]. World Health Organization (WHO) expressed that DM will turn

\footnotetext{
*Correspondence: Hasan.maleki@kums.ac.ir; kamyar.khoshnevisan@gmail.com ${ }^{\dagger}$ Hassan Maleki and Kamyar Khoshnevisan equally contributed as first authors to this review article

${ }^{1}$ Nano Drug Delivery Research Center, Health Technology Institute, Kermanshah University of Medical Sciences, Kermanshah, Iran

${ }^{2}$ Medical Nanotechnology and Tissue Engineering Research Center,

Shahid Beheshti University of Medical Sciences, Tehran, Iran

Full list of author information is available at the end of the article
}

into the seventh greatest reason for mortality in 2030 [4]. Numerous macrovascular/microvascular complications are associated with DM as an effect on vital organs in the body, including high risks of heart disease, peripheral vascular disease, kidney failure, neuropathy, retinopathy, and even lower extremity amputations [5]. As a result, exogenous insulin administration and other therapeutics are indispensable for regulating blood glucose levels. The conventional route of insulin delivery may be accompanied by pain, needle phobia, local tissue-damaging, and decreased compliance, as well as the risk of infection [6].

To obviate these restrictions, an immense variety of delivery methods were investigated to control blood glucose levels, including oral, nasal, pulmonary, and transdermal approaches, etc. [7-9]. Nevertheless, each of these methods encounters with some limitations including poor permeability across the barriers of body, possible allergic or irritation reactions, difficulty to achieve high plasma drug concentration, and low or variable original author(s) and the source, provide a link to the Creative Commons licence, and indicate if changes were made. The images or other third party material in this article are included in the article's Creative Commons licence, unless indicated otherwise in a credit line to the material. If material is not included in the article's Creative Commons licence and your intended use is not permitted by statutory regulation or exceeds the permitted use, you will need to obtain permission directly from the copyright holder. To view a copy of this licence, visit http://creativecommons.org/licenses/by/4.0/. The Creative Commons Public Domain Dedication waiver (http://creativeco mmons.org/publicdomain/zero/1.0/) applies to the data made available in this article, unless otherwise stated in a credit line to the data. 
bioavailability owning to degradation by proteolytic enzymes [10-17]. Therefore, using alternative delivery strategies is imperative to prevent limitation/problems and improve effectiveness as well satisfaction of diabetic patients. A number of nanostructure-based delivery systems were studied to conquer different DM-associated complications [18-20]. Therefore, NF-based systems have presented tremendous capabilities as delivery systems and as artificial scaffolds to deliver therapeutics agents and cells (Fig. 1).

As a delivery system or reservoirs, NFs can provide an adequate matrix for encapsulation and incorporation of therapeutic agents as well as able to prevent destruction before reaching their target sites with high-efficiency, and low-adverse effects. Such structures possess high flexibility in producing various morphologies (Fig. 2) [21], high drug-loading capacity (up to 60\%), and encapsulation efficiency (up to 100\%), as well as have the potential to deliver their content $[22,23]$. Therapeutic agents are loaded in the fibers by different methods, including a combination of agent with the polymer solution before spinning, producing core/shell structures through coaxial spinning, attaching active agents on the surface of the fiber, post-fabrication surface modification, and grafting on the surface $[24,25]$. These methods can be applied for more precise control over release kinetics and achieve timely release of therapeutic agents.

Artificial scaffolds can create three-dimensional (3D) fibrous frameworks that mimic the natural extracellular matrix (ECM) multi-fibril networks in design and structure which are mostly used as ECM substitutes to support the vital functions of cells [26, 27]. NF scaffolds with architectural similarity to native ECM can provide an immense surface area for cell-scaffold interaction/ adherence and effective exchange for oxygen and nutrition transportation. NFs can be incorporated with ECM proteins, growth factors (GF), and nanomaterials to promote the formation of tissue-like structures for tissueengineered implantation/transplantation [28].

Multifarious natural materials and synthetic polymers were exploited to synthesis NF structures for DM treatment. In general, natural polymers showed superior biocompatibility, suitable biodegradation, and significantly lower immunogenicity, whereas synthetic polymers can form electrospun much easier with good mechanical strength and high flexibility. To take the maximum advantages from those materials, using a combination strategy is recommended.

NF-based systems regarding several approaches were broadly applied in recent years for DM treatment (Fig. 1). Delivery of biomacromolecules e.g., insulin, GFs, small interfering RNA, as well as anti-diabetic chemical agents, is one of the most prominent features of NF-based structures for DM treatment $[29,30]$. Insulin can be incorporated/coated in NF patches to be administered via dermal/transdermal or by other routes e.g., sublingual to decline plasma glucose level. In particular, insulin-loaded dressings can promote the formation of a wound matrix

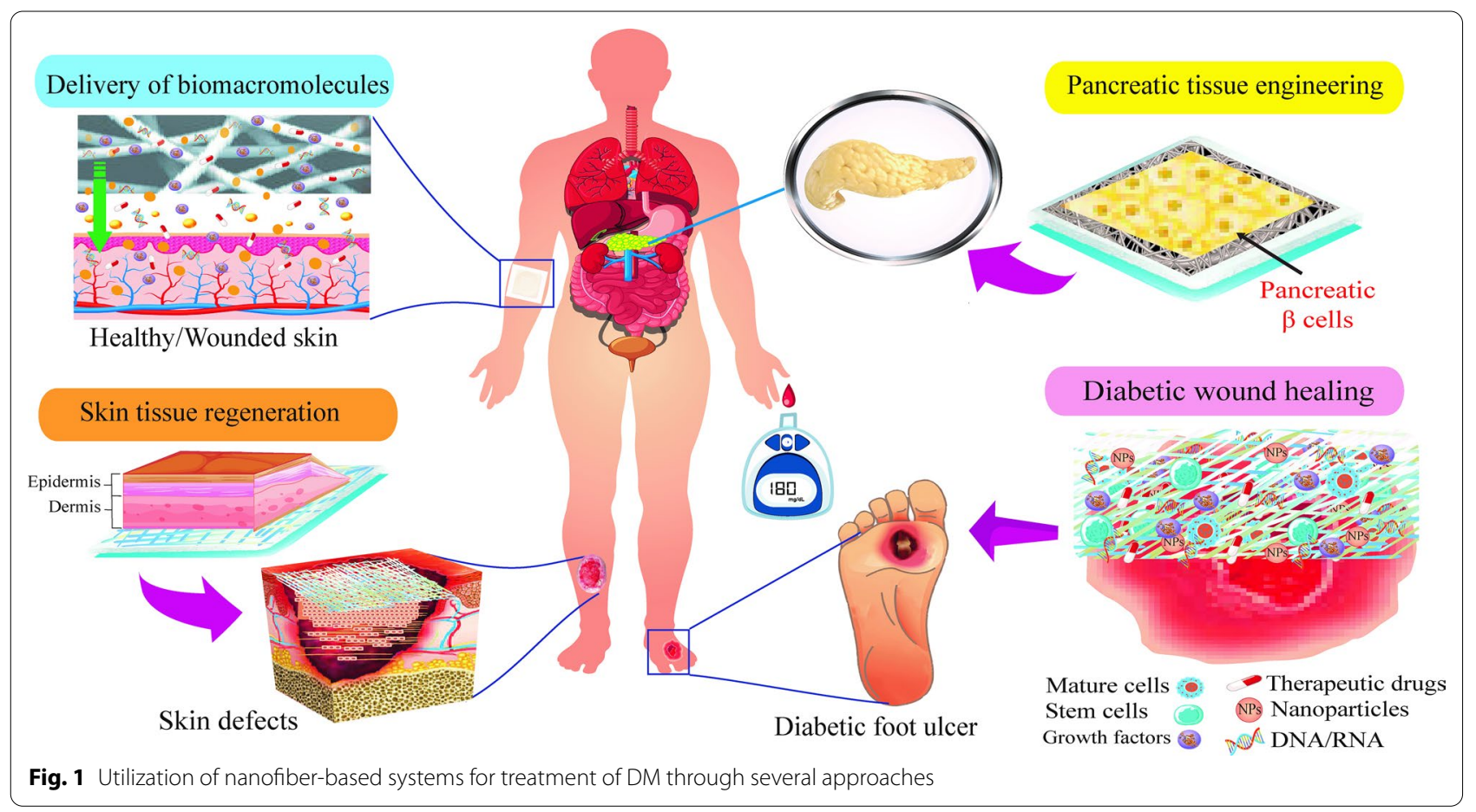



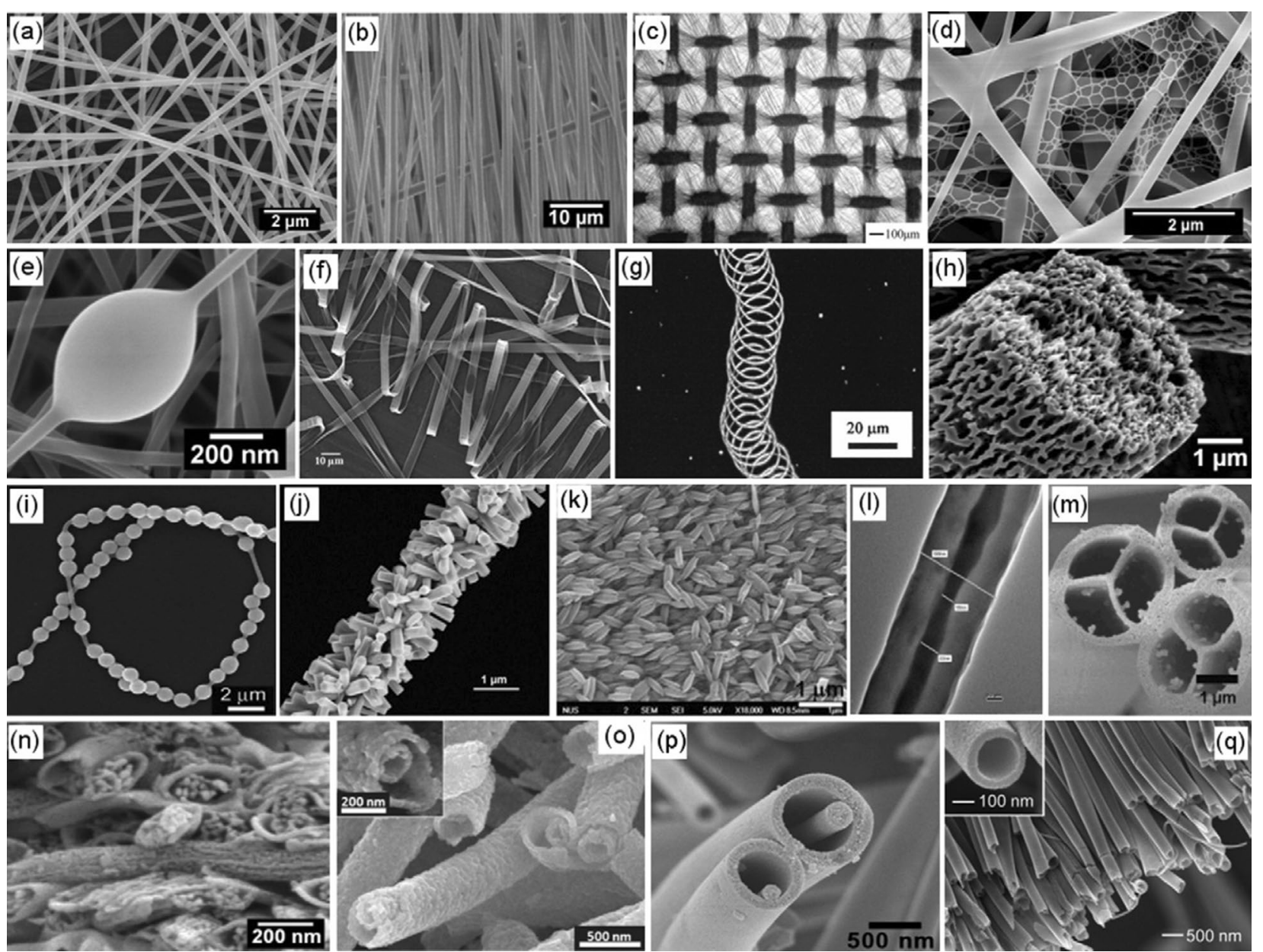

Fig. 2 Fibers with multifarious morphologies prepared by electrospinning. a-d Different NF assembly morphologies: a random oriented, b aligned as well as (c) patterned and (d) spider-web-like nano-fiber/net structures. $\mathbf{e - q}$ Various single NFs with (e) bead-on-string, (f) ribbon-like, (g) helical, (h) porous [30], (i) necklace-like, (j) firecracker-shaped, (k) rice grain-shaped, (I) core-shell, (m) multichannel tubular, (n) multi-core cable-like, (o) tube-in-tube, (p) nanowire-in-microtube and (q) hollow structures. Reproduced with permission from Ref. [21]

and accelerate wound healing in patients with DM [31, 32]. Furthermore, Genes and GFs can be incorporated within or onto NFs [33, 34]. These biomolecules stimulate cell proliferation, differentiation, angiogenesis, tissue repair, and regeneration. Hence, using locally controlled and efficient delivery to target cells e.g. NF scaffolds can achieve to further increase delivery efficiency or extend function duration, thereby could be fruitful to induce the healing of diabetic ulcers and promote cell's activities to skin or pancreatic tissue engineering (TE).

Diabetic Wound (DW) remains a major clinical challenge due to impaired healing process composed of multifactorial which resulted from peripheral neuropathy, impaired vascular function, impaired angiogenesis, and/ or chronic inflammation as well as microbial infection in chronic wounds $[35,36]$. By the inhibition of wound healing process, these complications resulted in delayed healing or even non-healing so which caused to $15 \%$ surgical amputation of all diabetic patients, despite a carefully calculated diet and intensive medical treatment [37]. Consequently, desirable wound dressings with biomimetic multifunctional features are indispensable to provide hemostasis, moisture retention, antibacterial effect, regeneration promotion capability, and ability to deliver bioactive agents. NF dressings/scaffolds are emerging technologies in wound healing making ECM-like networks that can deliver herbal/chemical drugs, GFs, and nanomaterials in a controlled manner as well as propel and promote cell proliferation and differentiation [28, 38, 39].

Pancreatic TE and $\beta$ cell replacement are another emerging areas in which NFs serve as a ECM-mimicking 
matrix for support and growth of islet $\beta$-cells and differentiation of stem cell-generated $\beta$ cells to treat DM. Using a bio-inspired hybrid scaffold is a novel approach to simulate pancreatic micro/nanoenvironment for preserving survival and function of cells as well as promoting cell differentiation into insulin-producing cells (IPCs) $[27,40]$. It seems that these 3D scaffolds are a considerable candidate to hinder the limitations of current $\beta$ cell production and islet transplantation (IT) to use in clinical pancreatic TE application.

Based on above-mentioned knowledge, the present study is focused on the capability of NFs-based platforms for therapeutics delivery, wound healing, and TE for DM treatment. At first, a brief description of electrospinning (ES) method as the most applicable technique for the fabrication of NFs and the characteristics of natural and synthetic polymers applied for NF preparation are described. Then, we have reviewed various studies related to the incorporation of drugs/genes/GFs in NFs-based delivery systems. Afterward, the capability of NFs for DW healing/dressing is discussed. Finally, we addressed the usability of NF scaffolds to function as artificial ECM in pancreatic $\beta$ cells replacement and TE for DM.

\section{Fabrication methods and characteristics of NFs}

As a significant matrix/scaffold, NFs are featured with small diameter, high porosity, high specific surface area, controlling of their composition, tailoring mechanical and surface features, and ease of synthesis [27, 41]. These structures possess proper sponginess for the absorption of exudates, highly permeable to water vapor, allowed an effective exchange of oxygen, water, and nutrient, and also can be functionalized with different molecular moieties [38]. The common strategies to create NFs include drawing solution blowing, self-assembly, template synthesis, phase separation, and ES [42, 43]. ES techniques are considered the most used technique to enable the fabrication of continuous fibers in the nanoscale dimension from a wide-ranging of either natural and synthetic polymer or a combination of both polymers. ES acts as a remarkably robust, versatile, and one-step technique for fabricating ordered and complex NF architectures using a high voltage electrical field applied to a polymer solution or melt $[44,45]$. Furthermore, fibers with varied morphologies could be fabricated via the control of processing condition and modifying standard set up of ES to produce nonwoven fibers with randomly aligned, straight aligned, core-shell, ribbon, porous structures, and so on (Fig. 2) [21, 46].

Electrospun NFs with desirable physical characteristics and high uniformity structure can be obtained by modulating the effective parameters, including parameters related to polymer solution, the electrospinning equipment, and environmental condition. Amid these, polymer solution parameters have a critical role in the formation of NFs with a broad range of sizes and morphologies, including concentration and molecular weight of polymer, solution conductivity, and solvent volatility. Viscosity and surface tension of polymer solution possess a decisive role in the morphology and size of electrospun NFs and are directly under the influencel of the molecular weight of polymer and solution concentration. Generally, low solution concentration that caused to low viscosity and high surface tension of the solution leads to the formation of beads and droplets, while very high solution concentration leads to blocking the capillary tip and disturbing rate of charged polymer flow leading to appear helix-shaped fibers and/or fibers could not be formed $[47,48]$. Besides, the molecular weight of polymer in a range suitable is necessary for the entanglement of polymer chains in solutions so that low molecular weight solutions resulted in the formation of beads instead of fibers and high molecular weight inclined to form microribbons [47, 49]. A proper solvent is crucial for the dissolution of polymer and the formation of fibers during the electrospinning jet elongation through the evaporation of solvent and phase separation. Applying solvents with a higher evaporation rate and boiling point can lead to the generation of surface roughness and pores on the surface fiber $[48,50]$. The other important parameter, the solution conductivity is determined by types of polymer, solvent, and salt. In this regard, by increasing conductivity the electrospinning jet carries more charges as well as NFs with smaller diameters and fewer beads can be produced $[49,50]$. Furthermore, the fabrication of NFs is affected by parameters related to the electrospinning process (e.g., applied voltage, tip-to-collector distance, and feed rate) and environmental parameters in the spinning chamber (e.g., temperature, humidity, and air velocity), which all of these parameters must be optimized [47-50].

In terms of length of NFs, they are produced and elongated continuously from a few pim to $^{\mathrm{m}}$ tens of meters with distinctive orientation and alignment that are required to cater to particular demands in the biomedical field [51, 52]. Moreover, diameter of NFs is proportional to the various fabrication parameters as mentioned earlier and could be adjusted from nanometer to microns [52]. Such extraordinarily small diameters can provide an extremely high surface-to-mass ratio (ranging from 1 to $35 \mathrm{~m} / \mathrm{g}$ depending on the fibers' diameter), high and interconnected porosity as well as high accessible sites for functionalization and immobilization [53]. Besides, with control over the NF diameter, its mode of encapsulation, and varying the morphology to core-shell type, the release kinetic from NFs mats can be modulated 
[54]. The diameter and morphology of electrospun NFs possess similar to the human ECM in terms of scale and morphology, thereby they have ability to accelerate the process of cell functions e.g., adhesion, proliferation, and differentiation [54, 55].

The mechanical properties of nanofibrous scaffolds/ mats are depended on the different structural parameters such as fiber diameter, alignment, porosity, and spatial distribution of NFs [43]. Both elastic modulus and strength of nanofibers significantly increase with declining fiber diameter that is attributed to increment in the crystallinity, the densely packed lamellae, and aligned fibrillar structures [56].

Porosity is another outstanding parameter of NFs that could be controlled the pore size distribution, by forming a highly open porous architecture and interconnected pore structure $[57,58]$. Thus, they have a beneficial effect on cell survival and proliferation as well as permit the transport of fluids and gases, the diffusion of nutrients, and prevention from bacterial infections [48]. Meanwhile, conventional hydrogels as another 3D cross-linked polymer matrices are capable of imbibing high water content, swelling without dissolving, and providing high porosity and elasticity $[59,60]$. However, such hydrogels often lack fibrous structures and the anisotropy features of native tissue ECM as well as possess insufficient mechanical strength [61]. Besides, precise control over porosity and the microarchitectural features of hydrogels still remained challenging issues [62]. In addition, several electrospun materials can able to form hydrogel NF systems with combined the desirable properties of both NF and hydrogel [63]. Particularly, porosity and swelling behavior significantly increased in hydrogel NFs due to their small pore size compare with conventional hydrogels [63].

\section{Characteristics of natural materials to NFs preparation}

Since the components of designed NF scaffolds should be located in proximity to native ECM, thereby they are frequently fabricated of natural, biodegradable, and biocompatible materials. Naturally occurring materials have garnered much interest in the field of biomedical applications due to better biocompatibility, biodegradability, low immunogenicity, and moderate mechanical stability compared to synthetic polymers [64]. Various biopolymers were utilized to make NFs for DM treatment which can be categorized into two major groups, polysaccharides and polypeptides; for instance, collagen, gelatin (Gel), silk fibroin (SF) of polypeptides, cellulose, chitosan (CS), hyaluronic acid (HA), and alginate from polysaccharides.

Collagen is the most prevalent fibrous protein in the ECM of connective tissues and comprised up to $30 \%$ of the total protein mass of a multicellular animal [65].
Collagen is formed by self-assembly of collagen triple helices, providing tensile strength, regulate cell adhesion, support chemotaxis and migration, and direct tissue development [66]. Denatured collagen, or Gel, has attracted a great deal of interest in NF synthesis, owning to its biological origin, biocompatibility, and excellent biodegradability with low immunogenicity and commercial availability at low cost [67]. The gel is derived from partial physical or chemical hydrolysis of collagen which is a soluble and amphoteric protein, enabling it to form a thermally reversible network in water because of alkaline and acidic amino acid residues $[68,69]$.

SF is amongst the most impressive natural materials is that abundantly utilized in a multitude of biomedical applications. SF is the main component of silk produced by some creatures like silkworms (Bombyx mori) [44]. The raw silk consists of two parallel fibroin filaments wrapped with the glue-like sericin protein [70]. SF is an amphiphilic block copolymer made up of hydrophobic and hydrophilic segments endowed with an amalgamation of remarkable tensile strength and toughness, good biocompatibility, perfect proteolytic degradability, and thermostability [44, 70].

Like other groups of biomaterials, polysaccharides are frequently applied to develop NF structures in terms of their innate physicochemical properties. Cellulose is considered the most profuse polysaccharide due to its ubiquitous nature and abundance as well as can be derivate to proper polymers for various utilizations. Thus, the most important acetate ester of cellulose, cellulose acetate (CA), is a biocompatible, biodegradable, renewable compound with excellent chemical resistance [71-73]. CA was broadly used for a broad spectrum of utilities in different engineered architectures/forms e.g., NF structures [74]. Besides, CA is used more than cellulose to make NFs because of more capability to ES to generate nanoscale fibers [71].

As de-acetylated derivative of chitin, CS is a heteropolysaccharide composed of glucosamine and Nacetyl glucosamine units linked by $\beta(1-4)$ glycosidic bonds. CS showed numerous inherent attributes e.g., biocompatibility, biodegradability, mucoadhesive ability, and anti-bacteria activity $[19,55,75]$.

HA is a non-sulfated glycosaminoglycan with the pleiotropic function which is found abundantly through body. HA merits attention for biomedicine applications due to its fascinating properties, comprising biocompatibility, biodegradability, non-immunogenicity, high water retention ability, and high viscoelasticity $[28,69]$. Moreover, HA enables to facilitate all phases of wound healing cascade and influences cell activities [19]. HAbased NFs were reported as being very considerable 
biomaterial for DW healing and developing bio-mimicking scaffolds for pancreatic TE applications.

\section{Characteristics of synthetic materials to NFs preparation}

Synthetic polymers possess especially benefits relative to natural polymers including easier ES with excellent mechanical strength, desired degradation rate, and proper thermal stability [55]. The most profuse synthetic polymers used the fabrication of NFs for diabetics' treatment can include polycaprolactone (PCL), poly vinyl alcohol (PVA), polylactic acid (PLA), poly lactic-co-glycolide (PLGA) copolymers, polyethylene glycol (PEG) as well as other less commonly used polymers e.g., polyethersulfone (PES), poly 3-hydroxybutyrate-co-3-hydroxyvalerate (PHBV), polyacrylonitrile (PAN) and so on. Although these polymers can be separately used to produce NFs, they are mostly applied in combination with other natural and synthetic materials to achieve higher or combined advantages.

PCL is a sufficiently biocompatible and slowly biodegradable polyester with high mechanical strength and good thermal stability which was intensively studied as worthy material for fabrication of $3 \mathrm{D}$ architectures $[27,29,44]$. PCL NFs provide mimic natural ECM for TE utilizations which are employed as long-term drug delivery carriers, although its hydrophobic nature resulted in poor cell attachment and proliferation [34, 55]. Combination with other hydrophilic polymers such as collagen, Gel, or CS and also high porosity on the surface of PCL NFs can obviate this limitation. PVA is other widely used synthetic polymers for NF fabrication for treating DM which is a water-soluble, nontoxic, biodegradable, and biocompatible polymer [55]. PVA NFs showed excellent mechanical properties and chemical resistance with a high swelling capacity $[19$, 55].

PLA is a natural-derived thermoplastic polyester which is very popular for NF fabrication. It is in terms of the unique characteristics such as favorable biocompatibility, excellent bioresorbable, and good solubility [76]. PLGA, the most well-known copolymer, is a food and drug administration (FDA)-cleared synthetic polymer which is widely applied thanks to its unique features e.g., non-toxicity, biocompatibility, and processability $[76,77]$.

As alluded to above, many types of NFs were applied for DWs treatment; however, unmet need for comprehensive investigation of therapeutic agents and cells delivery via nanofiber-based systems proposed for diabetic mellitus still remained. Thus, we aimed to focus the summary points of nanofiber-based systems effects on DM wounds as a novel therapeutic and preventive approach.

\section{Insulin delivery}

Insulin is a $5.8 \mathrm{kDa}$ protein which plays an important role in regulating metabolism and enhancement of cell growth $[78,79]$. The oral use of insulin is still challenging owing to easy degradation in the gastro-intestinal tract. Toward to end of prescribing insulin, several studies were carried out to develop the oral form of this protein [80, 81]. Some studies tried to encapsulate the insulin into the nanoparticle or fibers to prevent the degradation in the stomach and early intestine [82-84]. Besides, insulin can be applied to the skin directly for a sustainable release system. Therefore, we tried to focus on studies considered nanoparticles in adjuvant to insulin in scaffolds to utilize in cell cultures and develop oral insulin.

Asako Nishimura et al. applied insulin as a peptide model (PuraMatrix ${ }^{\mathrm{TM}}, \mathrm{PM}$ ), promoting drug delivery after injection of insulin via a self-assembling nanofiber hydrogel scaffold which is called PM-insulin sol (PM-Isol). The findings displayed that the plasma level of insulin was increased with an increment of PM-Isol concentration. Moreover, the bioavailability and hypoglycemic efficiency of insulin was increased after subcutaneous injection of the PM-Isol [37]. Another study by Yan et al. reported that they could construct a film from poly (vinyl alcohol-co-ethylene)/CS nanocomposite via a green and facile electrodeposition method. By decreasing $\mathrm{pH}$, the permeability of nanocomposite progressively increased. The releasing behaviors of this component can manage by the external imposing of electric signal [85]. Adnan Haider et al. carried out a study to develop tissue engineering in orthopedic surgery. They revealed that PLGA insulingrafted hydroxyapatite nanorods composite nanofiber scaffold had increased osteoblastic cell growth. It may indicate that this scaffold released appropriate insulin molecules and insulin to enhance osteoblastic proliferation [86].

Shih-Jung Liu et al. developed loaded insulin into biodegradable core-shell nanofibers from PLGA by leading the solution from Insulin and PLGA into two capillary tubes using two pumps. This study revealed that nanofibrous core-shell insulin-loaded scaffold could decrease the quantity of type I collagen and increase the transforming growth factor-beta (Fig. 3) [87].

Other study in Denmark that Karen Stephansen et al. performed applied the bioactive electrospun fish sarcoplasmic protein (FSP) for careering of small protein such as insulin to small intestine cells. Encapsulation of insulin can prevent insulin degradation by chymotrypsin and $12 \%$ increase of insulin transportation into cells by the interaction between nanofibers and Caco- 2 cells which leads to open of tight junction proteins [88]. In a similar study by S. R. Dhakate tried to develop a transdermal patch from nanofibers of PVA and sodium alginate 

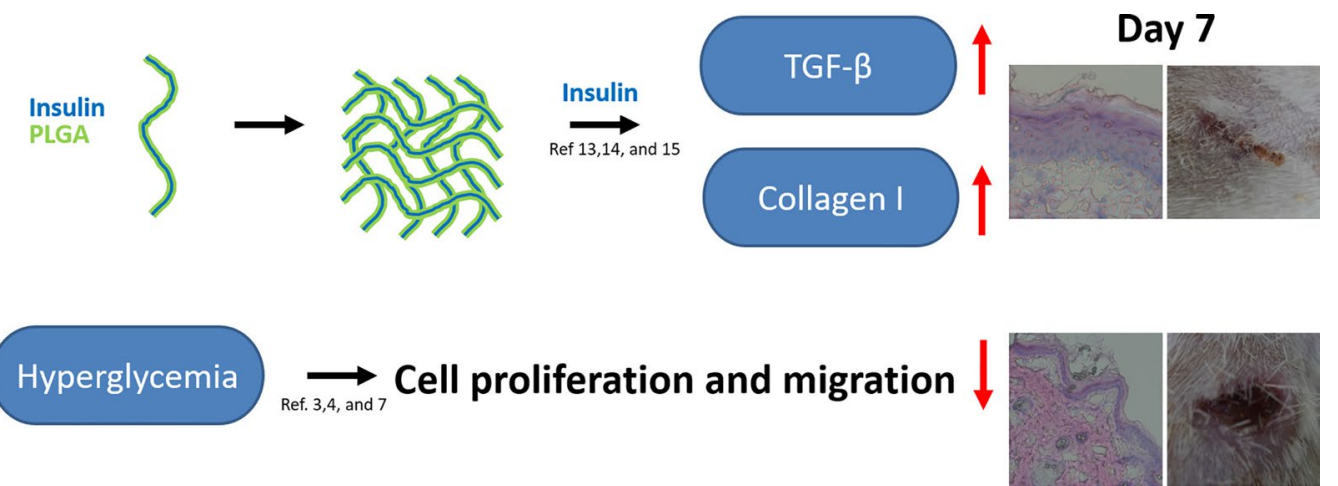

Fig. 3 Functionally active insulin released from insulin-loaded nanofibrous scaffolds to accelerate the healing wound Reproduced with permission from Ref. [87]

electrospun composite with loaded insulin. Insulin was released sustainably from the developed nanofiber patch which was compatible with the commercial formulation. An encapsulation efficiency provides a satisfactory indication which obtained nanofibers act as a perfect carrier for sublingually delivery of insulin [89].

Michael G. Lancina et al. used CS electrospun nanofiber polyethylene oxide scaffold to develop a carrier for insulin. Different ratios of Poly (ethylene oxide) (PEO) were utilized to regulate the morphology and physical characteristics of scaffold. They observed that a higher CS: PEO ratio in smaller fibers can result in more rapid insulin release. One interesting finding was that CS: PEO20 fibers 16 times higher preheatable to buccal cells compared to free insulin. They suggested that electrospun CS nanofibers may able to use to produce oral insulin components [90]. Table 1 shows the characteristics of mentioned investigations in detail.

It is believed that the conservation of the bioactive form of several biomolecules like proteins, growth factors, some other hormones, vitamins, and steroids for sustainable release from scaffold was required in tissue engineering. Besides, insulin-loaded scaffolds can be served as a sustainable release form to increase insulin proliferation. Several studies indicated that electrospun scaffolds can be suitable to apply in the wound and a combination of six biomolecules (vitamin C, hydrocortisone, insulin, triiodothyronine, epidermal growth factor, and dihydroxyvitamin D3 needs to add to scaffolds which gradually deliver these components to wound.

Table 1 Various characteristics of nanofibrous delivery systems incorporated with insulin

\begin{tabular}{|c|c|c|c|c|}
\hline $\begin{array}{l}\text { Type of } \\
\text { polymer/ } \\
\text { material }\end{array}$ & $\begin{array}{l}\text { Diameter of } \\
\text { nanofiber } \\
(\mathrm{nm})\end{array}$ & Applied cell type/animal & Main finding & Refs. \\
\hline PuraMatrix $^{\mathrm{TM}}$ & $-{ }^{\mathrm{a}}$ & Male Wistar rats & $\begin{array}{l}\text { PGLmarkedly decreased and maintained up to } 24 \mathrm{~h} \text { via subcutaneous } \\
\text { route }\end{array}$ & [37] \\
\hline PVA-CO-PE/CS & $100-600$ & - & Nanofibers with the electrochemically controlled release system & {$[85]$} \\
\hline $\mathrm{PLGA} / \mathrm{nHA}-\mathrm{I}$ & 520 & Osteoblastic cells (MC3T3-E1) & $\begin{array}{l}\text { Accelerate the cell adhesion, proliferation, and differentiation of the } \\
\text { osteoblastic cells }\end{array}$ & {$[86]$} \\
\hline PLGA & $432 \pm 106$ & Atrial fibroblasts/prague-Dawley rats & $\begin{array}{l}\text { Supported accelerated wound healing and favored epithelial cell } \\
\text { proliferation }\end{array}$ & {$[87]$} \\
\hline FSP & $360 \pm 37$ & Caco-2 cells & $\begin{array}{l}\text { Physically protect the degradation of insulin and increased transport } \\
\text { crossing the cell monolayer }\end{array}$ & {$[88]$} \\
\hline PVA/NaAlg & $300-400$ & Induced diabetes Wistar rats & $\begin{array}{l}\text { The composite nanofibers serve as an ideal carrier for the delivery of } \\
\text { insulin via the sublingual route }\end{array}$ & [89] \\
\hline CS/PEO & $200-2000$ & $\begin{array}{l}\text { 3T3-L1 preadipocyte cells/ex-vivo } \\
\text { porcine buccal mucosa }\end{array}$ & Nanofiber mats capable of delivering insulin via the buccal mucosa & {$[90]$} \\
\hline
\end{tabular}

${ }^{a}$ Not available data in the article

PuraMatrix ${ }^{\mathrm{TM}}$ acetyl-(Arg-Ala-Asp-Ala) ${ }_{4}-\mathrm{CONH}_{2}, P G L$ plasma glucose level, $P V A$ poly (vinyl alcohol), PE poly(ethylene), CS Chitosan, $P L G A / n H A-/$ poly(lactide-COglycolide)/insulin-grafted hydroxyapatite nanorods, FSP fish sarcoplasmic protein, NaAlg sodium alginate, $P E O$ poly(ethylene oxide) 


\section{Growth factors and gene therapy}

NFs decorates with different GFs and DNA, or RNA molecules are significant tools for diabetic ulcer treatment. Most small molecules delivered using NFs are intended to increase damaged cell viability, promote migration and their proliferation. Furthermore, GFs are used to increase angiogenesis around ulcers which affects healing process (Table 2).

GFs and genes delivery systems via NFs networks could be carried out via two different approaches. In first approach, bioactive molecules (i.e., proteins) form NFs network, which could carry GFs or act alone at the ulcer site. The latter was applied as biocompatible and biodegradable polymers to form NFs networks which act as a carrier.

The heparin-mimetic peptide was used to prepare bioactive NFs networks for IT. NFs were prepared during the self-assembly process, which is driven by noncovalent interactions [91]. Heparin-binding peptide amphiphiles (HBPAs) formed NFs networks via self-assembly process using PLA matrices. Then, the fiber was decorated by vascular endothelial growth factor (VEGF) and fibroblast growth factor 2 (FGF2) for IT. HBPAs protect GFs from proteolysis and activate them for signaling pathway. Moreover, the peptide affected GFs release in vivo and resulted in having more control on release profile [92].

PCL NF was used to design a carrier system for an endothelial growth factor (EGF) and graphene oxide (GO) simultaneously [93]. EGF in mixture with PCL and GO affected nitric oxide synthase 3 genes expression in the vascular VEGF pathway.

The combination of different polymers for NF synthesis was mostly employed in numerous studies due to designing a wide range of NF mesh in terms of physicochemical and mechanical properties. In combination with PEG as diblock copolymer, PCL was used for DNA delivery [94], small interfering RNA [94], plasmid human epidermal growth factor (phEGF) [95], and multiple GFs (i.e., basic fibroblast growth factor (bFGF)/EGF) [96]. Release control of DNA and RNA is usually done using linear polyethyleneimine (LPEI) immobilized on NF. LPEI linker was cleavaged by matrix metalloproteinase existed in high concentration at diabetic ulcer. The release profile of LPEI mediated NFs delivery systems were controlled by LPEI/NFs ratio [94, 95]. Different proteins could be simultaneously immobilized via different physical and chemical methods on NFs. The bFGF was loaded in coaxial electrospun PCL/PEG NFs, then EGF was attached on fiber surface using a simple peptide bond (i.e., amine group of the fiber and carboxyl group of the GF). The capability of NFs to design binary release systems resulted in accelerating wound healing [96]. PCL was electrospun with PCL-PEG block copolymer to form NFs mat having functional amine group on the surface. Then, amine group was used for EGF immobilization. Functional group density affected loading capacity and release profile of EGF, which was simply adjusted by PCL/PCL-PEG ratio [97].

PLA as another common polymer was used as PLGA [25, 98], PVA/PLA [23], poly (ethylene glycol)-poly(DLlactide) (PELA) [99] for NFs preparation which delivers platelet-derived growth factor (PDGF), Connective tissue growth factor (CTGF), and basic fibroblast growth factor (bFGF), respectively. The electrospun PDGF and PLGA/antibiotic were obtained using different needles to prepare co-axial sheath-core NFs. NFs sustain release antibiotic and GF preventing ulcer infection and promoting cell viability simultaneously [98]. PLGA-decorated cellulose nanocrystal (CNC) was used for the delivery of inflammatory mediators which affected diabetic foot ulcer (DFU) healing. PLGA/CNC NFs were prepared in one step by adding CNC in PLGA solution before ES process. CNC improved PLGA mechanical properties and increased cell response (attachment, migration, and proliferation) at diabetic ulcer sites in vivo [100]. In another work, PVA was used as a core polymer for CTGF delivery in core-sheath NFs. PLA as a sheet resulted in having a porous medium which facilitates release profile control [23].

NFs can deliver different small molecules to ulcer sites. As mentioned earlier, different proteins and nucleic acids were loaded inside of NFs or attached on the surface of fiber using functional groups. Using nanoparticles (NPs) that carry special GF incorporation by NFs results in increasing release time and loading capacity. Gelation NPs (GN) were used to VEGF and PDGF delivery systems which exploited collagen and HA as NFs mesh. VEGF-loaded GN and bFGF HA solution and PDGF/ VEGF-loaded GN and EGF collagen solution were electrospun during dual source dual power process. The obtained NPs-decorated NFs released four different GFs simultaneously (Fig. 4), which revealed the potential and capacity of NFs to deliver bioactive agents [101].

\section{Cell delivery and tissue engineering}

Currently, one of the most effective methods for DM treatment is the replacement of IPCs using TE and regenerative medicine approaches. In this regard, IT, pancreatic TE, and cell replacement therapy by assisting fibrous scaffolds have emerged as powerful platforms with immense potential in DM treatment.

IT has been suggesting a perpetual treatment for DM patients which was providing some progress in clinical practice. Besides, It is divided into intrahepatic and extra-hepatic sites, proposing its advantages and disadvantages [104-107]. Several restrictions and limitations 


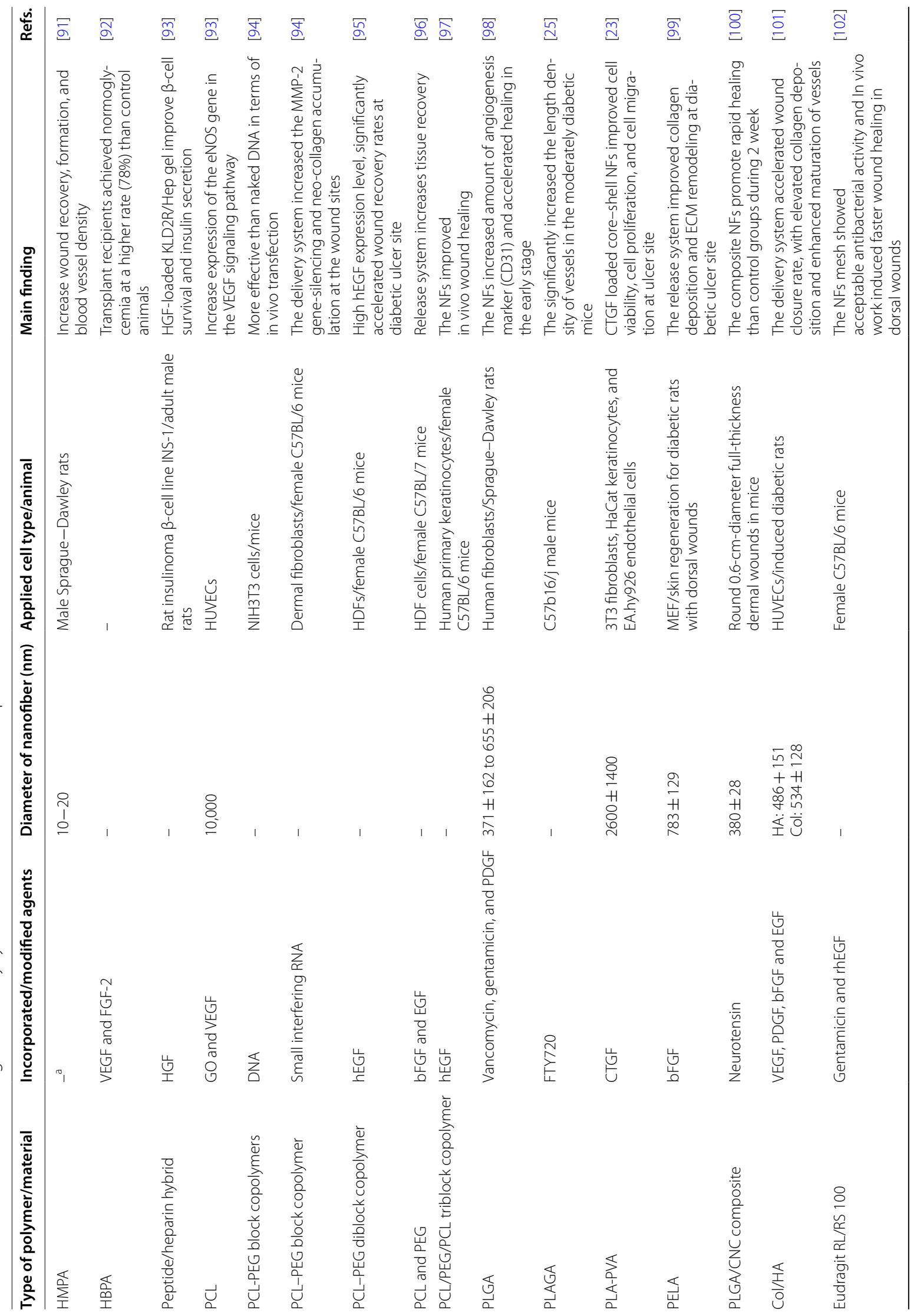




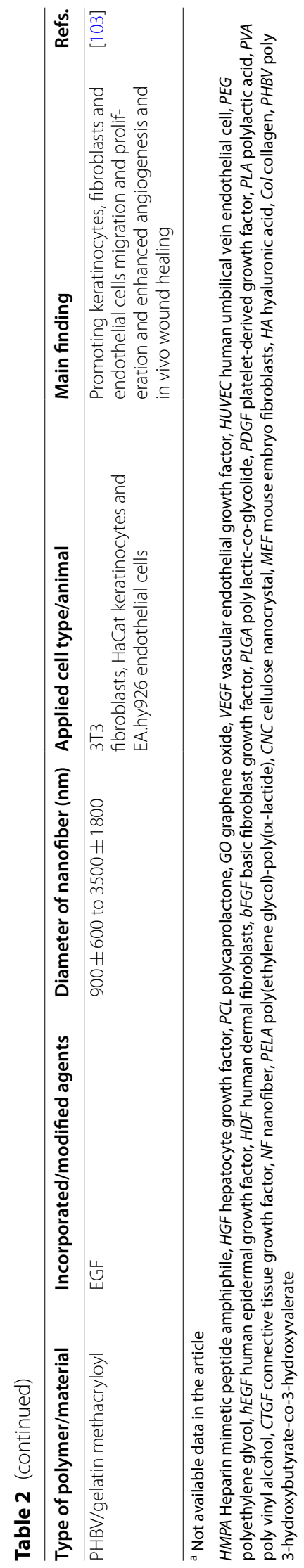




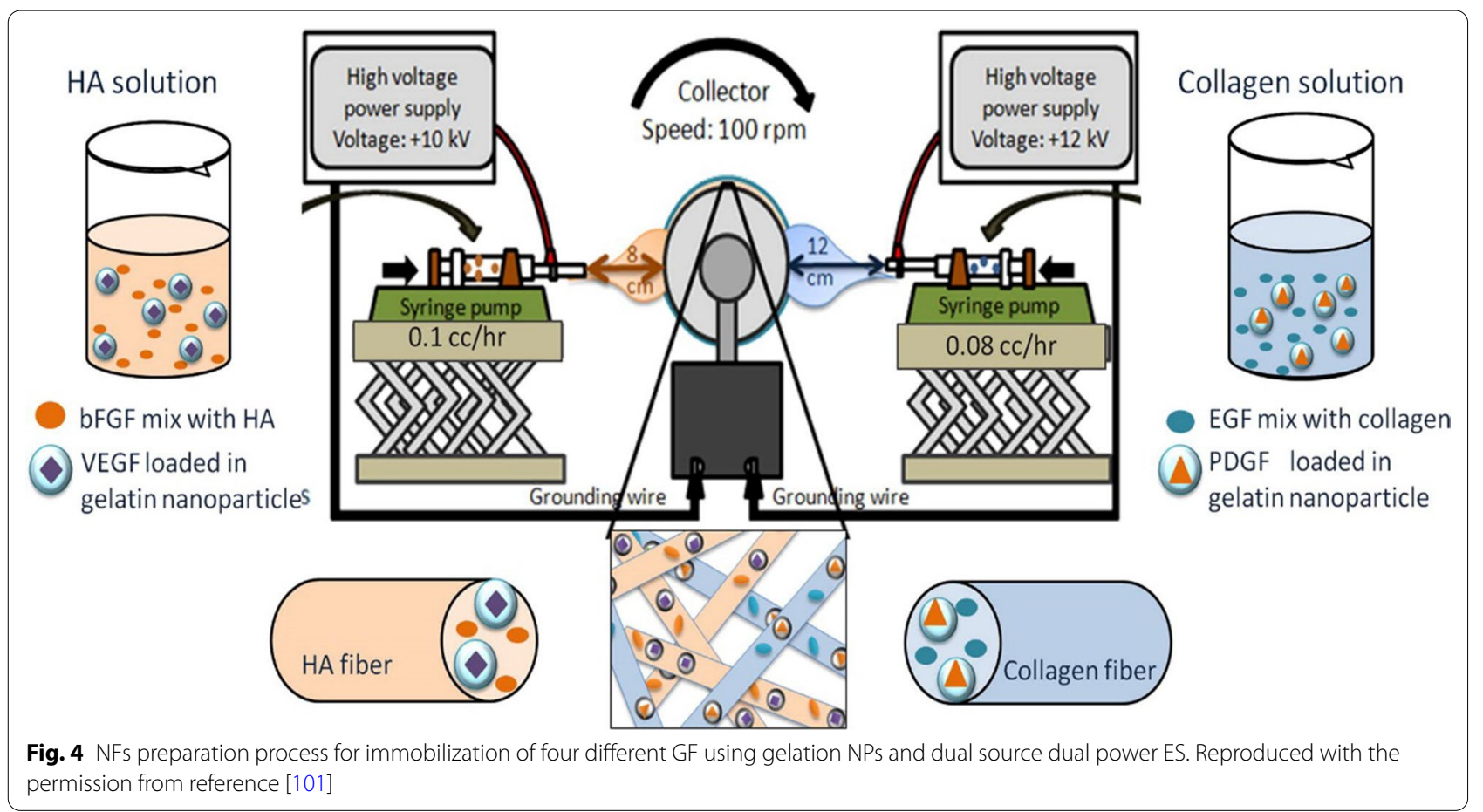

are present for the islet transplant procedure mostly maintaining viability and the functionality of islets after transplantation are limited by the loss of integrity and destruction of blood vessel networks as well as lack of proper access to nutrients and GFs [95, 108]. Moreover, the development and clinical application of IT have encountered some restrictions including insufficient donor source for transplantation, damage to the ECM of islets during the process of isolating by collagenase and patients need to take immunosuppressive agents for a lifetime [76, 109]. Therefore, it is essential to establish a suitable mechanically and biologically supportive scaffold/environment to improve islet culturing and transplantation efficiency. In this regard, NF systems open a new avenue to design advanced nanoenvironments for IT.

The preliminary study for developing NF scaffolds intended for islet cell transplantation was undertaken by Saahir Khan et al. [110]. They developed a glucagonlike peptide 1-mimetic peptide amphiphiles (PA) selfassembled NF gels to encapsulate RINm5f cells which could enhance insulin release and proliferation of encapsulated $\beta$-cells. Another PA NF, heparin mimetic nanofibrous gels, was employed in the long-term culture of islets as a new therapeutic approach for type 1 DM. The findings indicated that ECM-like environment by PA NFs provided with the ability to enhance islets viability, angiogenesis, and more efficient IT [95].
The possibility of PCL electrospun NF scaffold for an increment of growth and differentiation was confirmed as a good nanoenvironment for the differentiation of human-induced pluripotent stem cells (iPSCs) to endodermal cells (as precursors of hepatocytes and pancreatic cells) which revealed high viability, growth, and differentiation [70]. In another study, a biomimetic hybrid scaffold composed of electrospun SF and pancreatic decellularized ECM was developed for islet survival that had shown improved islet survival and promoted insulin secretion [111]. Whereas, the differentiation capability of conjunctiva mesenchymal stem cells (MSCs) into IPCs were studied on natural SF NFs and compared with synthetic PLA NF scaffolds which resulted in more pancreatic gene expression and higher insulin secretion by synthetic scaffolds [102]. Furthermore, the potential of unadulterated synthetic scaffolds including CA, PES, and polytetrafluoroethylene as active materials for islet cell encapsulation was evaluated. ES process can cause induced hydrophobicity to electrospun membranes which restrict cell attachment, preserving their inherent organization and cells maintained in an aggregated form compared to commercial ones [112]. In another pancreatic TE study, Yang B et al. subcutaneous space had chosen as an extra-hepatic site for IT. PVA/silicone NFs conjugated with VEGF were applied for subcutaneous IT [113]. The corresponding procedure is represented in Fig. 5. They found that modified NFs had no deleterious effect on cell viability, raised neovascularization, 
A

Prevascularization

in diabetic mice

B

Islet extraction

from normal mice

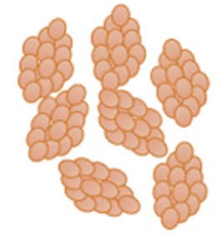

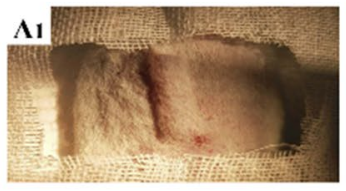

14 days

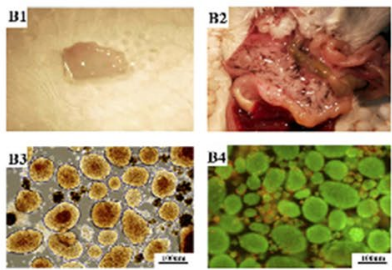

1 day

\section{C}

Islet transplantation

in diabetic mice
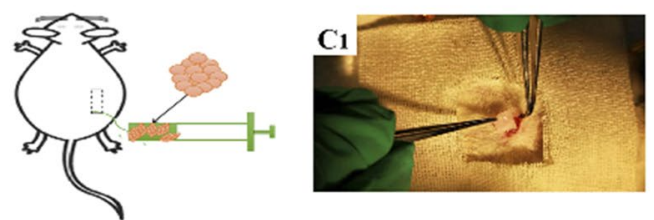
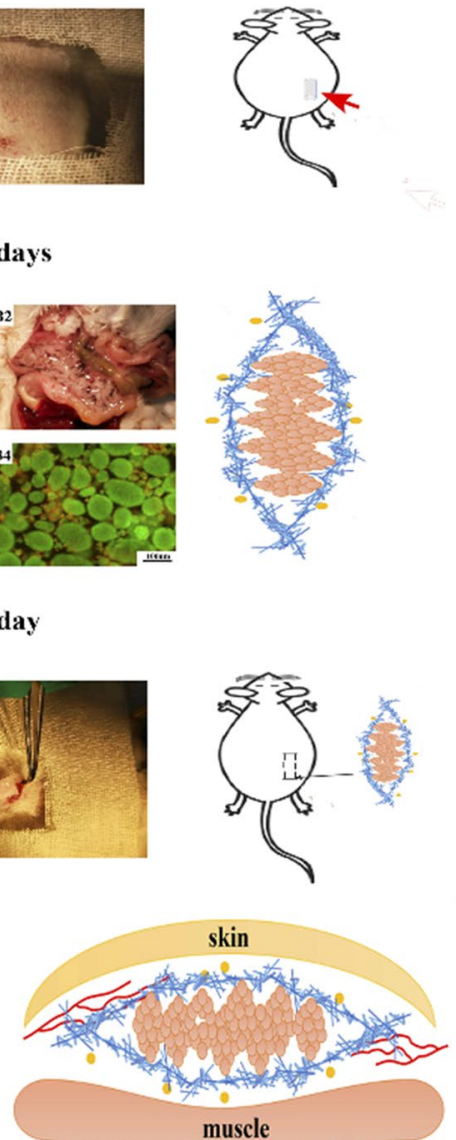

Fig. 5 Schematic illustrating the device-less (DL) procedure and DL in the combination of $\mathrm{SiO}_{2}$-VEGF scaffolds for IT at subcutaneous. It comprised of 3 steps including: A A silicone/nylon catheter was pre-implanted subcutaneously (A1) (red arrow) to prevascularization and removed after 14 days; $\mathbf{B}$ islet isolation and $\mathrm{SiO}_{2}$-VEGF NFs wrapping (Blue mats =NFs, yellow dots =VEGF). (B1: wrapped islets; $\mathrm{B} 2$ : expanded mouse islet for isolation; B3: syngeneic islets are isolated and collected $(\mathrm{bar}=100 \mu \mathrm{m})$; B4. islet viability is detected by live/dead assay $($ bar $=100 \mu \mathrm{m})$ ); $\mathbf{C}$ islet or wrapped islet (C1) transplantation in the prevascularized percutaneous cavity in diabetic mice. Reproduced with the permission from reference [113]

and induced mild inflammation, thereby the function of subcutaneously transplanted islets was augmented in diabetic mice.

Cells, scaffolds, and growth-stimulating factors are the main triad for TE and cell delivery. Numerous studies were undertaken to provide the right environment for pancreatic islet seeding and culture. At this point, NF scaffolds have attracted great attention for pancreatic TE due to their plentiful benefits. Sojoodi et al. reported the culture of rat islets on synthetic laminin-coated polyamide electrospun NFs that induced comparable gene expression to adult $\beta$ cells and enhanced maintenance of functional islets [114]. Besides, coating $\beta$ cell membranes onto PCL/poly-D-lysine electrospun NFs offered a natural environment recapitulating cell-cell interaction and significantly enhanced $\beta$ cell function and proliferation rate [115]. In similar studies, the pancreatic differentiation capacity of induced iPSCs into IPCs on electrospun PES NFs [116] and collagen-coated PES NFs [117] were evaluated. The finding reveals that both scaffolds caused the expression of pancreatic tissue-specific markers and proteins at a high level and promoted differentiation of hiPSCs into IPCs.

In another study published by Enderami et al., PLA/ PVA scaffolds were exploited as a substrate for the differentiation of iPSCs into IPC [118]. It was reported that the expression of pancreas-specific transcription factors considerably increased and IPCs formed sphericalshaped cell aggregations morphologically was similar to that of pancreatic islet cells [118]. Likewise, the same 
NF scaffolds were applied to promote the differentiation of adipose-derived mesenchymal stem cells (ADMSC) into IPCs which resulted in a long time IPCs survival and function of cells [119]. The transplantation of pancreatic $\beta$ cell precursors derived from human Wharton's jelly MSCs by culturing on PLA/CS NF scaffold in a diabetic mice model resulted in a significant decline in blood glucose level and an increase in insulin levels after transplantation [120]. Moreover, the possibility of PLA/ CS nano-scaffold treated with zinc oxide ( $\mathrm{ZnO}) \mathrm{NPs}$ to differentiate human endometrial stem cells (EnSC) into IPCs was assessed aiming at DM cell therapy [121].

As other NF scaffold, SF was constructed to simulate the pancreatic microenvironment for differentiation of iPSCs into IPCs which significantly evoked proliferation of the hiPSCs and its differentiation potential into IPCs [122]. Furthermore, IPC differentiation potency of hADSCs was examined on a hybrid NF scaffold composed of SF and PES polymers. This hybrid scaffold provided an in vivo-like $3 \mathrm{D}$ microenvironment, enabling to promote the proliferation and differentiation of hADSCs into IPCs [123]. Recently, a cell-co-polymer complex constructed from PHBV NFs was developed to differentiate human iPSCs into IPCs which increased the survival of iPSCs, the amount of IPC relevant genes and insulin secretion [124].

As a proper candidate for cell therapy and pancreatic TE in a diabetic's autologous transplantation, hADSCs, were applied to induce efficient differentiation into IPCs in the presence of PVA NFs and platelet-rich plasma. The differentiated IPCs showed the expression of beta cell markers of differentiation together with enhanced proliferation capability and insulin production [125]. Abazari et al. fabricated a 3D NF scaffold comprised of PCL and PVA polymers which provided a suitable synthetic ECM for the improvement differentiation of hiPSC to IPCs [126]. The differentiation potency of human endometrial stem cells (EnSC) from definitive endoderm cells on PAN scaffolds in culture medium containing Y-27632 molecules was also confirmed that the expression of pancreatic precursor markers elevated considerably. Subsequently, differentiated cells transplanted into the peritoneal cavity and/or injected via the tail of diabetic rats that the former caused a lower blood glucose concentration, and the latter was more effective in increasing the bodyweight of rats [127].

Thanks to the ability to mimicking native ECM architecture using electrospun NFs, cell-based therapies have warranted enormous attention in DW healing and skin regeneration. PCL-Gel scaffold associated to $\mathrm{CD}^{+} 3^{+}$ hematopoietic stem cells was used as a suitable tissueengineered construct in DW healing. They found that the $\mathrm{CD}_{93}{ }^{+}$cells are enabled to accelerate the healing and closing of diabetic ulcers by upregulating VEGF expression level and downregulating death-associated protein kinase 1 expression level at the wound sites [128]. In a subsequent study, wound healing effects of 3D scaffolds comprised of radially-aligned and/or vertically-aligned NFs in conjunction with bone marrow MSCs were evaluated for DW healing applications [129]. 3D scaffolds were capable of enhancing the biological functions of laden cells, regulating the local inflammation, and allowed wounds to heal via promoting angiogenesis, improving the formation of granulation tissue, and increasing collagen deposition. Moreover, the results showed that radically-aligned scaffold could accelerate wound healing via the re-epithelialization of superficial wounds (DFU = stages $0-1$ ) and vertically-aligned scaffold was able to enhance the formation of granulation tissues of deep wounds (DFU = stages 2-3) (Fig. 6) [129].

An exclusive multi-functional TE architecture was constructed with GO-PEG synthesized with quercetin (Que) and then loaded on the surface of artificial acellular dermal matrix (ADM) scaffolds (ADM-GO-PEG/Que), which can provide the biodegradable, biodegradable, cell-adhesive substrates with great stability. The resulting hybrid scaffold meaningfully promoted MSCs adhesion, proliferation, and differentiation into osteoblast and adipocyte as well as accelerated DW healing by promoting collagen synthesis and improving capillary construction [130].

Table 3 represents some of the main features of abovementioned studies in this section. This table provides the characteristics of polymers/materials, incorporated/ modified agents, and the fiber diameter of scaffolds as well as the differentiated cell type and their main achievement/applications.

\section{Therapeutics delivery for wound healing}

Wound healing is one of the most sophisticated, highly regulated processes in the human body that is crucial for the restoration of tissue integrity and maintaining the barrier function of the skin. It involves the spatial and temporal synchronization and interplay of several cells, growth factors, and cytokines. It consists of sequential phases as the natural progression of a completely healed wound, including hemostasis, inflammation, proliferation, and remodeling, occurring within the immediate hours, days 1-4, days 4-21, and days 21-years after an injury, respectively [131]. Wounds can be caused by nonpathologic or pathologic conditions such as diabetes. A diabetic skin ulcer is one of the foremost complications of DM which can cause severe disorders e.g., DFU and even lower extremity amputations [132]. Numerous investigations were considered the potential procedures of therapeutic agents- loaded electrospun NF mats as a 


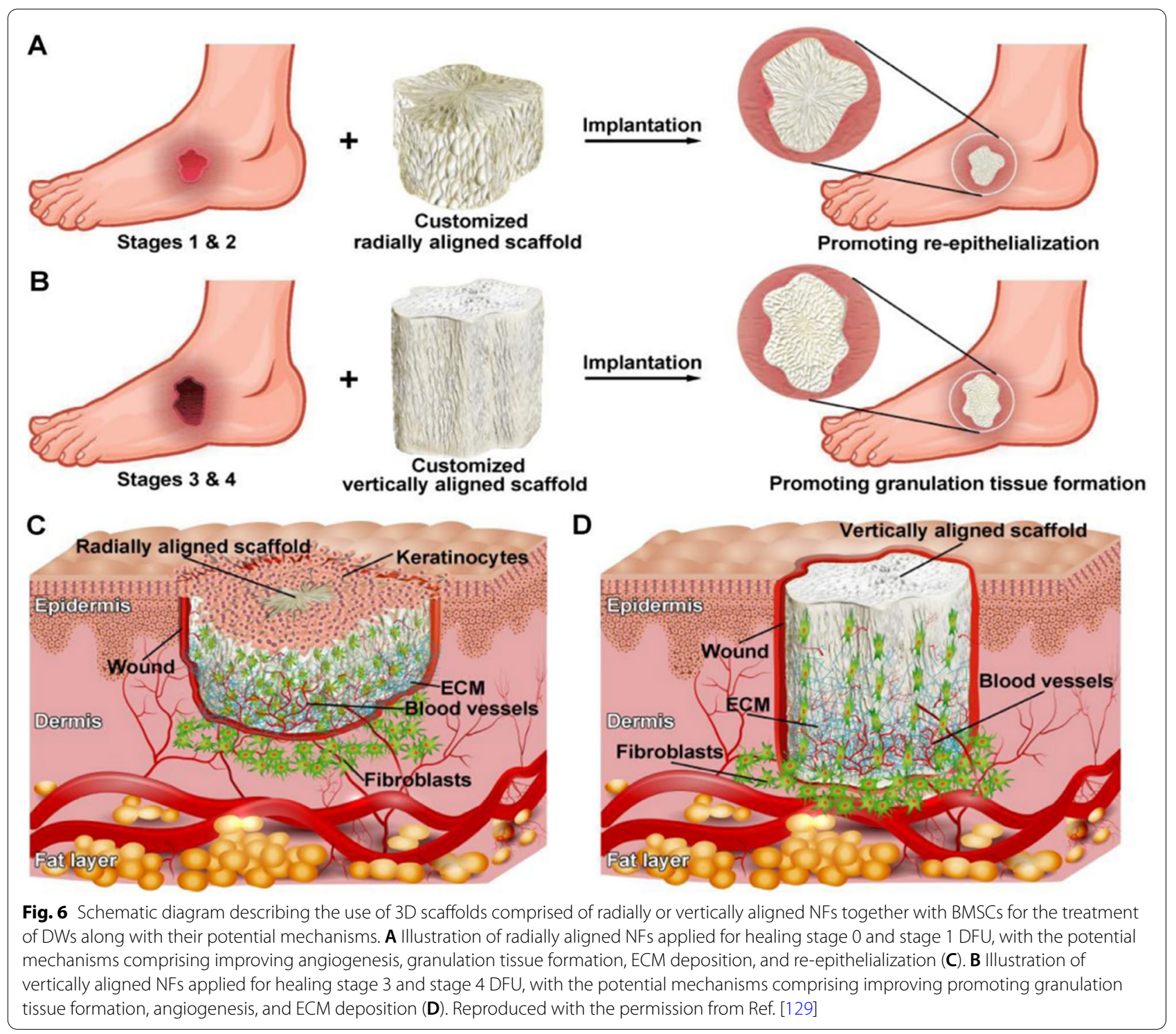

wound dressing to rapidly regenerate the structural and functional properties of injured skin in patients with DM [132-138]. Among these agents, antidiabetic drugs such as metformin (Met) and glibenclamide received much attention. Besides, the various synthetic and natural materials, including a blend of biocompatible and biodegradable polymers with or without the mentioned agents were extensively applied to fabricate NFs for wound healing applications.

For this purpose, we attempted to represent all capable polymers used as a wound dressing, including PVA/ PCL, hydrogel-based, CS-based, cellulose-based, metalbased, and miscellaneous NF mats intended for DW. Besides, we investigated all in vitro and in vivo studies which examined the application of different therapeutic agents-loaded NF systems to treat DM or its complications e.g., DWs.

\section{PVA/PCL-based mats PVA-based mats}

Regarding small-molecule, Sena et al. produced PVA/ PLA core-shell NFs containing Met that resulted in sustained release and good cell compatibility intended for DW healing [139]. Basha et al. prepared an electrospun fibrous scaffold containing PVA/curdlan blend by the addition of silver nitrate-based antimicrobial activity. The results from in vitro and in vivo studies presented noteworthy wound healing and better cell spreading and faster healing of removal wounds in diabetic rats, respectively [140]. In another study, Chouhan et al. investigated 
Table 3 The characteristics of fibrous scaffolds applied in cell delivery and TE intended for treating DM

\begin{tabular}{|c|c|c|c|c|c|}
\hline Type of polymer/material & $\begin{array}{l}\text { Incorporated/modified } \\
\text { agents }\end{array}$ & Diameter of fibers $(\mathrm{nm})$ & $\begin{array}{l}\text { Applied cell type to } \\
\text { differentiation }\end{array}$ & $\begin{array}{l}\text { Main achievement/ } \\
\text { application }\end{array}$ & Refs. \\
\hline Glucagon-like peptide 1 & $-^{a}$ & 10 & Rat insulinoma cells & $\begin{array}{l}\text { A proper cell-encapsulating } \\
\text { network for enhanced } \\
\text { activity and proliferation } \\
\text { of IPCs }\end{array}$ & [110] \\
\hline $\begin{array}{l}\text { Heparin mimetic peptide } \\
\text { amphiphilic }\end{array}$ & VEGF and FGF2 & $20-30$ & Pancreatic islet & $\begin{array}{l}\text { Nanofiber gel platform for } \\
\text { islet culture and transplan- } \\
\text { tation }\end{array}$ & {$[95]$} \\
\hline $\mathrm{PCL}$ & - & 200 & hiPSCs & $\begin{array}{l}\text { An ideal scaffold for dif- } \\
\text { ferentiation of hiPSCs in 3D } \\
\text { culture }\end{array}$ & {$[70]$} \\
\hline $\begin{array}{l}\text { SF and pig pancreatic } \\
\text { decellularized ECM }\end{array}$ & - & $97-707$ & Mouse islet & $\begin{array}{l}\text { A promising candidate for } \\
\text { pancreatic TE }\end{array}$ & [111] \\
\hline CA, PES, and PTFE & - & $\begin{array}{l}365 \pm 136(\text { (CA) } \\
224 \pm 140 \text { (PES), } \\
261 \pm 140 \text { (PTFE) }\end{array}$ & - & $\begin{array}{l}\text { Potential for islet cell } \\
\text { encapsulation application }\end{array}$ & [112] \\
\hline PVA /Silicone & VEGF & $4-10$ & Mouse islet & $\begin{array}{l}\text { The ECM to improve the } \\
\text { vitality of subcutaneous } \\
\text { islet transplantation }\end{array}$ & [113] \\
\hline SF/PLA & - & - & $\begin{array}{l}\text { Conjunctiva } \\
\text { MSCs }\end{array}$ & $\begin{array}{l}\text { A potential supportive } \\
\text { matrix for islet TE }\end{array}$ & [102] \\
\hline Polyamide & Laminin & - & Pancreatic $\beta$ cell & $\begin{array}{l}\text { Providing an ECM-like } \\
\text { system for islet culture }\end{array}$ & [114] \\
\hline PCL/poly-D-lysine & MIN6 cell membrane & $50-280$ & Pancreatic $\beta$ cell & $\begin{array}{l}\text { As scaffolds to culture beta } \\
\text { cells }\end{array}$ & [115] \\
\hline PES & - & - & hiPSCs & $\begin{array}{l}\text { A } 3 D \text { matrix to enhance } \\
\text { pancreatic differentiation } \\
\text { of hiPSCs }\end{array}$ & [116] \\
\hline PES & Collagen coating & - & hiPSCs & $\begin{array}{l}\text { As a potential scaffold } \\
\text { for pancreatic TE and } \\
\text { regenerative medicine } \\
\text { applications }\end{array}$ & [117] \\
\hline PLLA/PVA & Oxygen modification & - & hiPSCs & $\begin{array}{l}\text { As an ideal scaffold to pro- } \\
\text { vide a microenvironment } \\
\text { for pancreatic differentia- } \\
\text { tion }\end{array}$ & [118] \\
\hline PLLA/PVA & - & - & hADSCS & $\begin{array}{l}\text { A suitable option in pan- } \\
\text { creatic TE }\end{array}$ & [119] \\
\hline PLA/CS & - & 70,000 & $\begin{array}{l}\text { Human Wharton's jelly } \\
\text { MSCs }\end{array}$ & $\begin{array}{l}\text { A precursor for cell trans- } \\
\text { plantation for diabetes } \\
\text { treatment }\end{array}$ & [120] \\
\hline $\mathrm{PLA} / \mathrm{CS}$ & - & $70-100$ & EnCSs & $\begin{array}{l}\text { An ideal scaffold for IPCs } \\
\text { development for diabetes } \\
\text { mellitus cell therapy }\end{array}$ & [121] \\
\hline Silk & - & - & hiPSCs & $\begin{array}{l}\text { A great potential to use } \\
\text { in clinical pancreatic TE } \\
\text { application }\end{array}$ & [122] \\
\hline Silk/PES & - & - & hADSCs & $\begin{array}{l}\text { As a supportive matrix to } \\
\text { mimic } 3 D \text { in vivo microen- } \\
\text { vironment }\end{array}$ & [123] \\
\hline PHBV & - & $900 \pm 600$ & hiPSCs & $\begin{array}{l}\text { As a promising cell- } \\
\text { copolymer construct for } \\
\text { pancreatic TE }\end{array}$ & [124] \\
\hline PVA & Oxygen plasma & - & hADSCs & $\begin{array}{l}\text { A new approach for } \\
\text { pancreatic TE and } \beta \text { cell } \\
\text { replacement therapies }\end{array}$ & [125] \\
\hline PCL/PVA & - & - & hiPSCs & $\begin{array}{l}\text { A new approach to beta- } \\
\text { like cells replacement } \\
\text { therapies and pancreatic TE }\end{array}$ & [126] \\
\hline
\end{tabular}


Table 3 (continued)

\begin{tabular}{|c|c|c|c|c|c|}
\hline Type of polymer/material & $\begin{array}{l}\text { Incorporated/modified } \\
\text { agents }\end{array}$ & Diameter of fibers (nm) & $\begin{array}{l}\text { Applied cell type to } \\
\text { differentiation }\end{array}$ & $\begin{array}{l}\text { Main achievement/ } \\
\text { application }\end{array}$ & Refs. \\
\hline Polyacrylonitrile & - & 250 & Human endometrial cells & $\begin{array}{l}\text { Transplantation of pancre- } \\
\text { atic precursor from endo- } \\
\text { metrium for the treatment } \\
\text { of diabetes }\end{array}$ & [127] \\
\hline PCL/gelatin & - & - & $\begin{array}{l}\text { Rat } \mathrm{CD}^{+} 3^{+} \text {hematopoietic } \\
\text { stem cells }\end{array}$ & $\begin{array}{l}\text { As a more appropriate tis- } \\
\text { sue-engineered construct } \\
\text { in DW repair }\end{array}$ & [128] \\
\hline PCL/pluronic-F-127 & - & - & Bone marrow MSCs & $\begin{array}{l}\text { Personalized 3D scaffolds } \\
\text { with controlled structure } \\
\text { for DW healing }\end{array}$ & [129] \\
\hline $\begin{array}{l}\text { Natural and artificial acel- } \\
\text { lular dermal matrix }\end{array}$ & $\begin{array}{l}\text { Graphene oxide- PEG- } \\
\text { mediated quercetin }\end{array}$ & - & MSCs & $\begin{array}{l}\text { A suitable architecture and } \\
\text { environment for cell attach- } \\
\text { ment and proliferation }\end{array}$ & [130] \\
\hline
\end{tabular}

${ }^{a}$ Not available data in the article

$P C L$ polycaprolactone, hiPSCs human-induced pluripotent stem cells, CS Chitosan, SF silk fibroin, VEGF vascular endothelial growth factor, FGF2 fibroblast growth factor 2, TE tissue engineering, ECM extracellular matrix, CA cellulose acetate, PES polyethersulfone, PTFE polytetrafluoroethylene, PVA polyvinyl alcohol, PLA polylactic acid, PLLA poly (L-lactic acid), MSC mesenchymal stem cell, $h A D S C$ human adipose-derived stem cells, $h E S C s$ human embryonic stem cells, EnSCs endometrial stem cells, IPCs insulin-producing cells, $P H B V$ poly(3-hydroxybutyrate-co-3-hydroxyvalerate), $P E G$ polyethylene glycol

wound healing efficiency of dressings generated of various SF diversities blended with PVA intended for alloxaninduced diabetic rabbit model. The results confirmed that the potential of non-mulberry SF (NMSF)-based bioactive dressings could regulate ECM deposition resulting in earlier and widespread treatment of chronic diabetic cutaneous wounds [141].

\section{PCL-based mats}

Curcumin (Cur), a plant-derived polyphenolic compound with anti-inflammatory, anti-bacterial, anti-oxidant, and angiogenic characteristics, was incorporated in two different NFs scaffolds, including PCL/GT and PCL, which enhance healing properties in both of them [142]. Fabrication of Cur-loaded PCL/gum tragacanth (GT) (PCL/ GT/Cur) electrospun NFs with/without MSCs were investigated for wound healing in diabetic rats as well as antibacterial activity of these mats was studied. The resultant obtained from final mats with MSc approved that all quantification analysis of mats can be more potent than GT/PCL/Cur NFs [143]. In a similar study, the fabrication of electrospun PCL/Gel NFs loaded with Aloe Vera (AV) and Hypericum perforatum oil (HPO) was individually considered for the wound healing applications. Obtained results revealed that HPO-loaded mats played an effective role in healing DWs than AV [144]. In another study, Bixin, a carotenoid derived from the seeds of the Annatto plant (Bixa orellana L.) with antioxidant and anti-inflammatory activity, was loaded to PCL NFs as a wound dressing which alleviates scar tissues and accelerates DW healing [145].
Based on a novel approach, Zehra et al. designed to improve PCL-based oxygen-releasing electrospun mats and assess their value for enhancement of wound healing process in diabetic rats. The experimental results, including cell studies, chorioallantoic membrane, and histological assessment indicated that PCL-sodium percarbonate dressings could constantly generate oxygen within 10 days. The developed oxygen-generating mats could be applied for well-organized recovery of chronic DWs [146].

Some studies have applied the combination of antidiabetic agents to enhance the wound healing properties of NF wound dressing. In a study conducted by Cam et al. pioglitazone (Pio), Met, and glibenclamide were loaded alone or in combination (Pio and Met or Pio and glibenclamide) with either CS/Gel/PCL or Polyvinylpyrrolidone (PVP)/PCL NF scaffolds by ES and pressurized gyration, respectively to compare their efficacy in DW healing. Their results suggested that CS/Gel/PCL scaffolds loaded by the combination of Pio and Met offer a suitable choice for DW dressing [147]. In a similar study, Yu et al. successfully prepared an asymmetric wettable composite mat with an extremely hydrophobic outer layer including PCL on nylon mesh with microporosity as well as the hydrophilic inner layer was attained using ES of Piomerged Gel-Pio for DW healing (Fig. 7). The developed mat can boost the wound healing process by stimulating cell proliferation, angiogenesis, collagen deposition, and re-epithelialization [148].

Rehman Khan reported an electrospun poly (L-lactide-co-caprolactone) (PLCL) NF loaded with $\mathrm{ZnO}$ NPs and oregano essential oil, applying a novel loading 


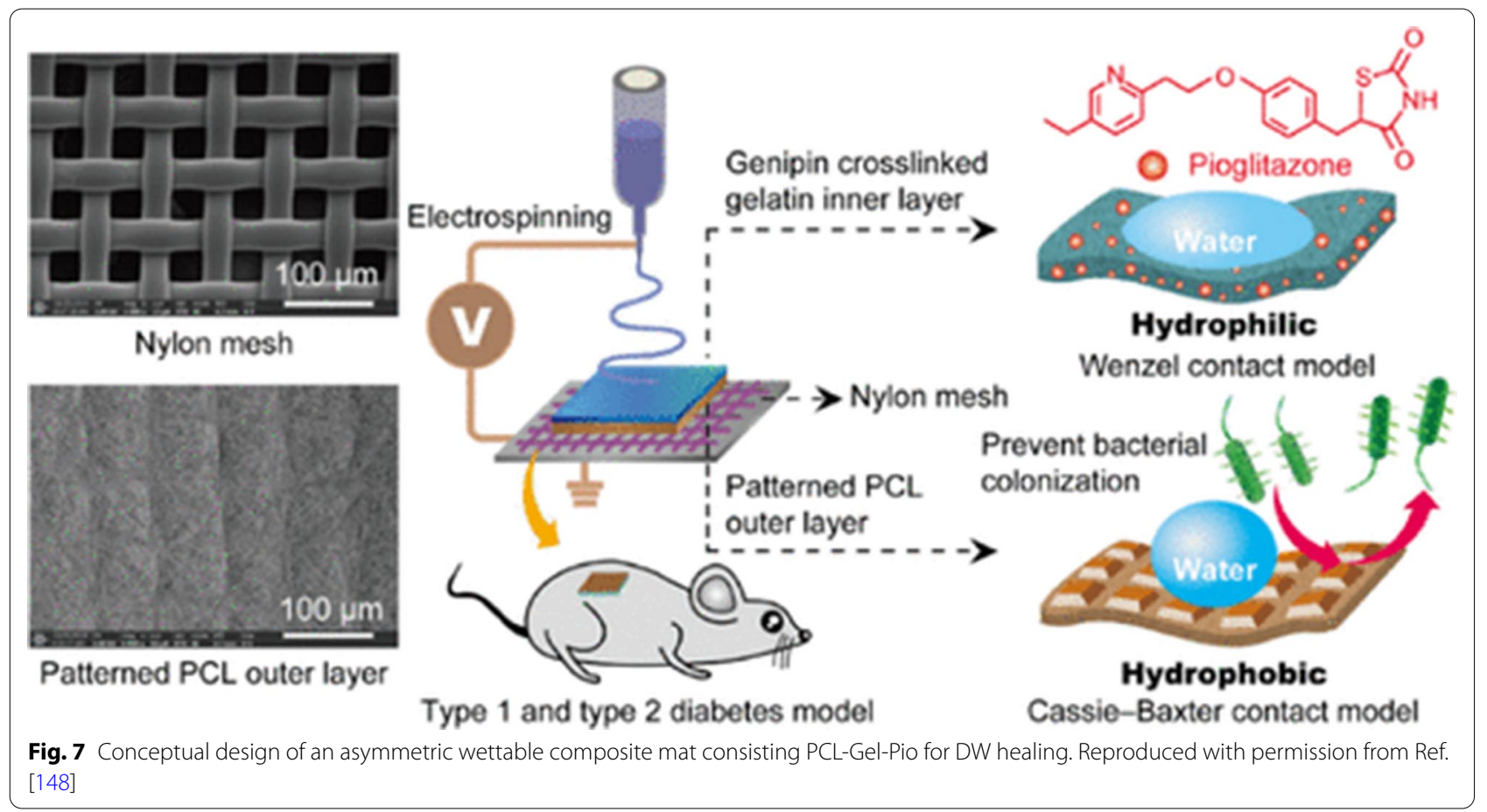

approach, able to sustainedly co-deliver bioactive agents. The bioactive mats critically drove the angiogenesis through the expression of VEGF. Furthermore, the proposed system effectively completed the inflammatory cycle using inhibiting pro-inflammatory cytokines interleukin-6 (IL-6) and matrix metalloproteinases-9 (MMP9) [149].

$\mathrm{Lv}$ et al. designed a conducive PCL/Gel NF scaffold loaded by nagelschmidtite $\left(\mathrm{Ca}_{7} \mathrm{P}_{2} \mathrm{Si}_{2} \mathrm{O}_{16}\right)$ particles, a silicate-based bioceramic, for DW dressing (Fig. 8). The composite scaffolds released the silicate ions in a sustained release manner during the degradation of NFs and showed accelerating wound healing by induction of collagen deposition, re-epithelialization, and angiogenesis [150].

Dimethyloxalylglycine (DMOG) can improve angiogenesis and tissue repair by inhibiting prolyl hydroxylases, an enzyme responsible for the degradation of hypoxia-inducible factor- $1 \alpha$ (a key transcription factor which regulates angiogenesis in hypoxic conditions; e.g. wounds microenvironment). In one study, Goa et al. presented DMOG-loaded mono-axial and co-axial PCL/

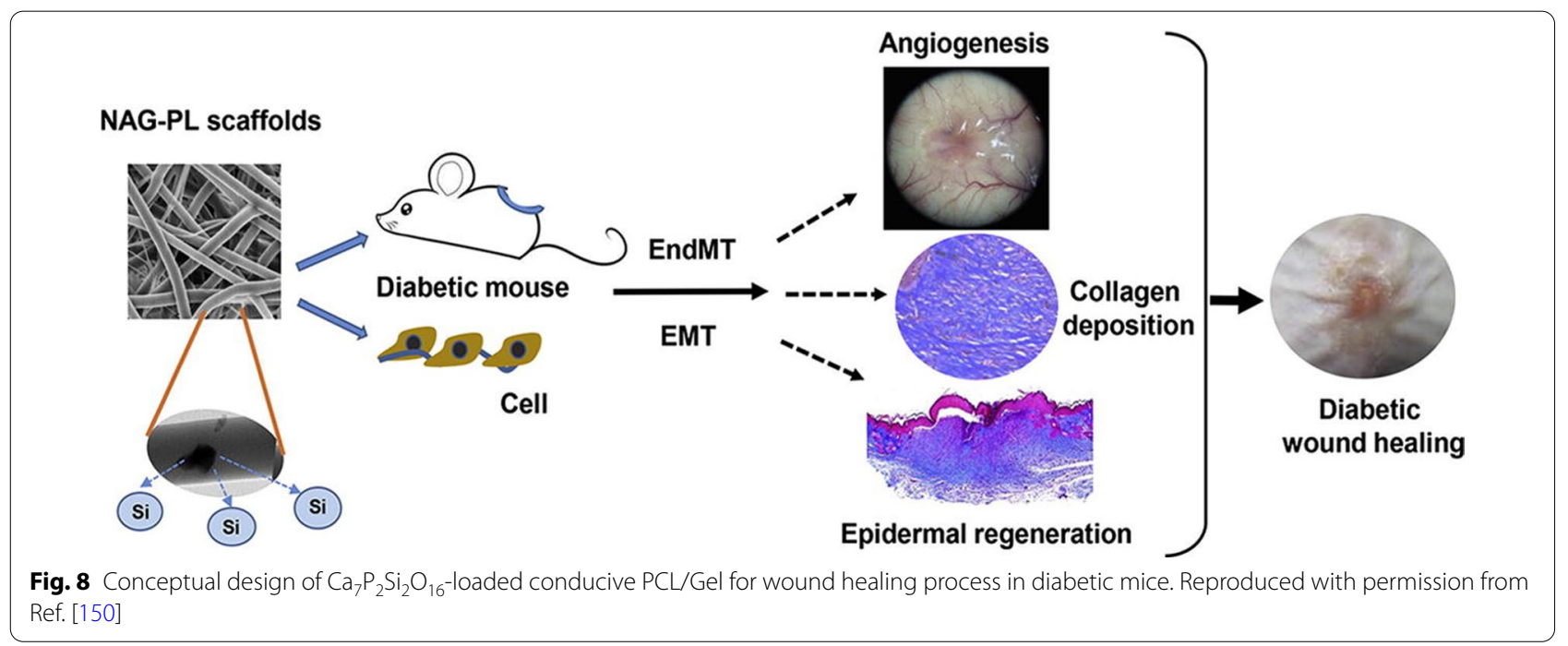


collagen for the wound healing process. The results confirmed that proposed system stabilized local hypoxiainducible factor $1 \alpha$ levels in wounds and consequently enhanced the DW regeneration by speeding up re-epithelialization angiogenesis [151].

\section{PVA-PCL mats}

Fabrication and characterization of electrospun scaffolds including GT, PCL, and PVA were studied to heal diabetic ulcers. Histological analyses of mats holding stem cells into diabetic rats displayed tissue healing and regeneration consisting of re-epithelization and collagen formation within 15 days. Finally, the authors concluded that made-up NFs with remarkable mechanical and biological characteristics are promising scaffolds in wound healing of diabetic ulcers [152].

Gholipour-Kanani et al. fabricated different combinations of CS: PVA and PCL: CS: PVA electrospun biological scaffolds on diabetic dorsum skin wounds and diabetic foot wounds on rat models. Pathological results showed much better healing efficacy for test samples as well as proved the presence of more pronounced granulation tissues in scaffold-treated wounds compared with the control ones [153].

\section{Nanofibrous hydrogel-based mats}

Liu et al. developed an absorbable NF hydrogel containing electrospun thioether grafted hyaluronic acid NFs (FHHA-S/Fe) for a synergistic pattern of inflammation microenvironment to speed up chronic DW healing (Fig. 9). FHHA-S/Fe treatment was more effective on the chronic DW model than that of FHHA/Fe without grafted thioethers, specifically in the initial wound healing stage. Hence, this simple dressing plan with fundamental dual modulation mechanisms of the wound inflammation microenvironment could play an impressive and safe therapeutic strategy for chronic DW [133].

In a similar study, self-assembling NF gel encapsulatedpolydeoxyribonucleotide (PDRN) were fabricated to discover the treatment efficacy of chronic wounds in the diabetic animal model. The results obtained from human embryonic (HE) staining and immunohistochemical confirmed that poly- $N$-acetyl glucosamine (sNAG), and

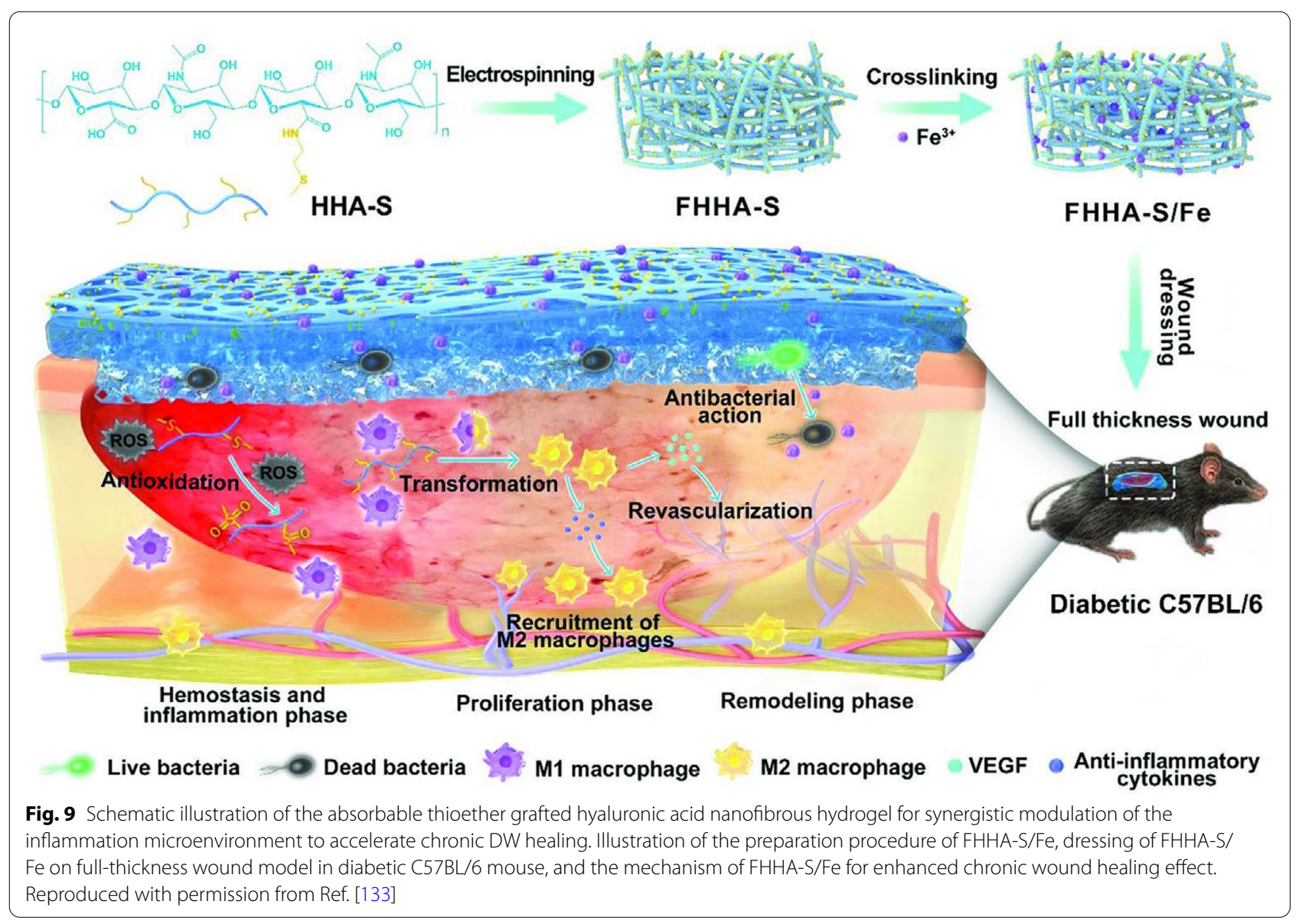




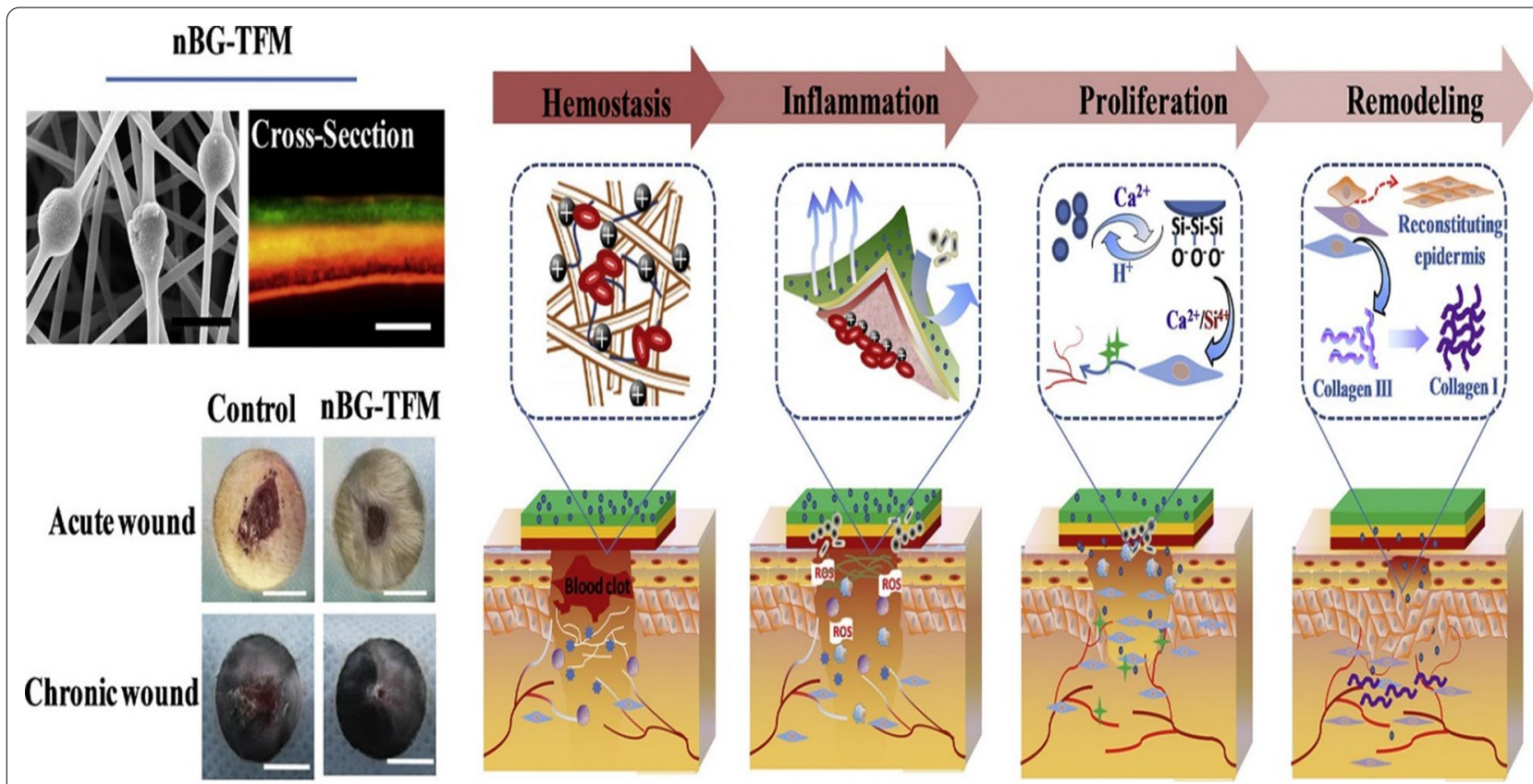

Fig. 10 Schematic illustration of CS-PVA- electrospun NFs intended for chronic and acute wounds. Reproduced with permission from Ref. [162]

sNAG encapsulated-PDRN might ameliorate wound healing [154].

A novel wound care hydrogel-based product consisting of turmeric, oregano, and CS NPs diminishes inflammation, clear infection, and enhances wound healing in ulcers in diabetic rats. The proposed system can be applied as an effective scaffold in diabetic and non-DWs. This combination can also be applied as a potent new product that is antibacterial, anti-inflammatory, and antioxidant even though in low concentration [155].

TEMPO-oxidized sacchachitin nanofibers (SCNF) and microfludized SCNF were fabricated to form a 3D gel structure as an ideal hydrogel-based mat. The proposed hydrogel-based mats exhibited greater potentials in tissue regeneration as well as accelerated DW healing due to their exclusive physical and chemical properties [156]. Beta-glucan $(\beta G)$, a major component of saccharomyces cerevisiae cell wall with immunomodulatory properties which can improve angiogenesis and tissue repair by inhibition of prolyl hydroxylases. In hydrogel-based study, $\beta$ G-loaded hydroxypropyl methylcellulose and polyethylene oxide were prepared to improve DW healing [157].

\section{Chitosan-based mats}

Chogan et al. also showed that using a three-layer mat containing two PCL-CS layers on each side and an inside layer of PVA-Met could stimulate wound healing and mitigate skin fibrosis by down-regulation of genes involved in fibrosis [158]. Ahmadi Majd et al. fabricated PVA/CS electrospun NF wound dressings and used them to induce in diabetic rats. Obtained results revealed that PVA/CS NFs significantly improved wound healing in diabetic rats [159]. In another study, Ahmed et al. applied a mixture of CS, PVA, and $\mathrm{ZnO}$ as an effective possibility for an accelerated healing process owing to the wound healing activities of CS-PVA NFs and the antibacterial ability of $\mathrm{ZnO}$ [160].

Gel-based electrospun NFs, including Cur and Lithospermi radix extract were electrospun onto CS scaffolds to produce bilayer NF scaffolds as well as the final mat was applied to enhance the wound healing process in diabetic rats. The proposed mat indicated high antiinflammatory effects and a satisfying recovery rate within 7 days for chronic DW [161].

Chen et al. prepared nanobioglass integrated CS-PVA trilayer electrospun NF membrane (nBG-TFM). The asprepared membrane indicated outstanding biocompatibility, antibacterial activity, and regeneration promotion effect (Fig. 10). The obtained system displayed shed new light on scheming functional wound dressings, which can ameliorate the healing of chronic wounds [162].

\section{Cellulose-based mats}

Bacterial cellulose (BC)/Gel NFs loaded with glybenclamide and Met were produced using a transportable electrohydrodynamic gun for DW healing by Emin Cam et al. (Fig. 11). This study's results revealed both antidiabetic 

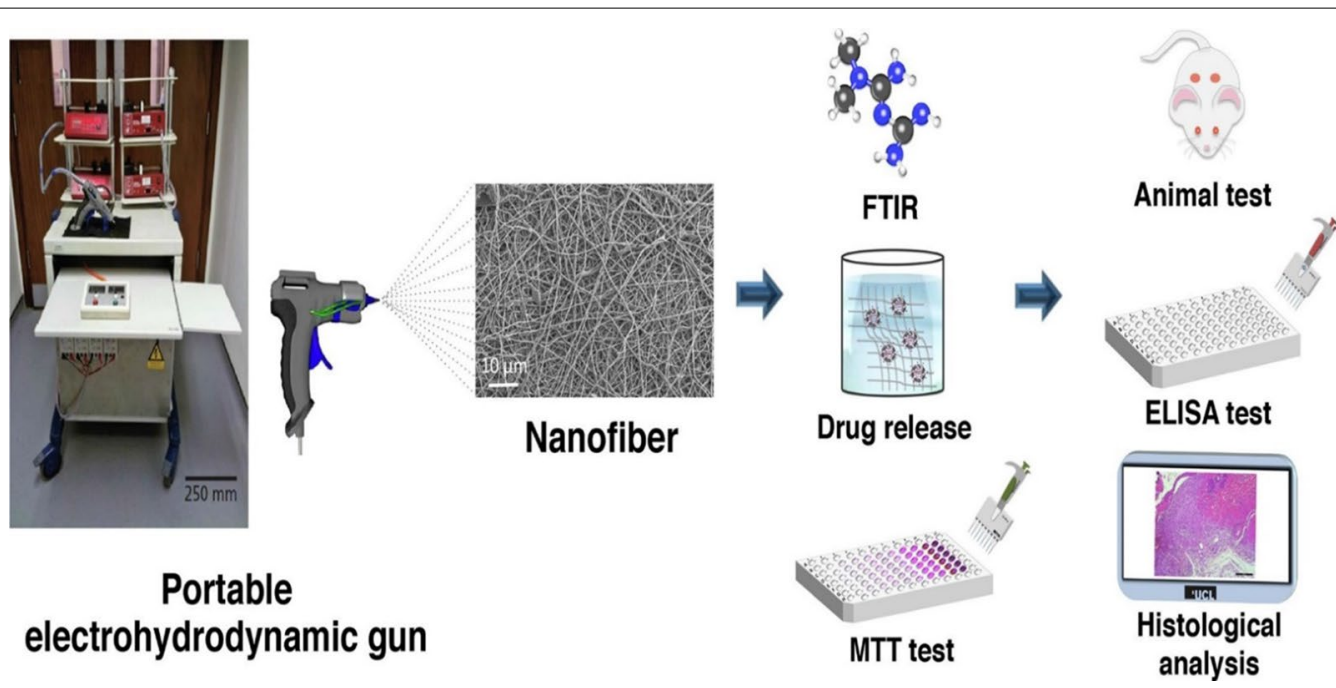

Fig. 11 Schematic illustration of BC/Gel mats loaded with Gb and Met. Reproduced with permission from Ref. [163]

drugs-eluting dressing enhance DW healing. However, glibenclamide loaded scaffolds had better results [163].

Sesamol, one of the phenolic compounds of a sesame seed, was loaded into CA-zein composite NF that resulted in accelerated reepithelization and improvement in DW healing [164].

Almasian et al. prepared a new polyurethane (PU)based NF scaffolds with different amounts of carboxymethyl cellulose (CMC) comprising Malva sylvestris extract, and they assessed their consequence on DW healing process. The extract-loaded PU/CMC presented high collagen deposition and neovascularization in treated DW compared with a gauze bandage and bare PU/CMC [165].

\section{Metal-based mats}

Li et al. prepared a cobalt-based metal-organic framework (MOF, ZIF-67) into micro-patterned PLLA/Gel NF scaffolds as a carrier for loading a small molecular drug (DMOG). The results confirmed that cobalt-based metal-organic framework as a dual cooperative controllable release system provides a new strategy for eliminating inflammation, enhancing collagen deposition and angiogenesis, and promoting DW healing [166].

El-Lakany et al. used copper (Cu)-grafted GOcrosslinked zein scaffolds as a DW dressing and showed promising results [167]. In another study, an electrospun Cu-based MOF (HKUST-1) was presented as a NO-loading carrier, and a NO sustainable release system with the core-shell structure was considered (Fig. 12). The results confirmed that endothelial cell growth could meliorate and remarkably enhance angiogenesis, collagen deposition as well as anti-inflammatory property in the scaffolds which ultimately speed up DW healing [168].
Jiang et al. reported a spaced-oriented electrospun scaffold with silicon-doped amorphous calcium phosphate nanocoating on the surface (Si-ACP/PM). The study pointed out that $\mathrm{Si}-\mathrm{ACP} / \mathrm{PM}$ can notably improve the angiogenesis process for DW healing, as well as can display great potential for DW healing therapy [169].

\section{PLGA-based mats}

In some investigations, Met was incorporated in NF wound dressing to get advantages of their properties. In this regard, Met-eluting dressing made from PLGA by ES showed a controlled release profile over 3 weeks and also supported re-epithelialization and accelerated cutaneous wound closure in the early stages of DW healing [170, 171].

H.T. Liao et al. fabricated aligned Cur-loaded PLGA NF membranes (PC NFMs), followed by merging of heparin to produce PLGA/Cur (PCH) NFMs for DW healing (Fig. 13). Obtained results from this study confirmed that NFs along with grafted heparin and Cur could easily absorb the key GFs for the wound healing process, via lessening the high oxidative stress and the inflammatory cascade [172]. In a similar study, SF and PLGA were applied for the fabrication of a hybrid membrane. The results obtained from histopathological evaluation outcomes proved that these potent mats could potentially be applied for wound healing with or without biological agents [160]. In the case of large molecules, liraglutide (Lira), a glucagon-like peptide-1 (GLP1) receptor agonist, was applied as an antidiabetic agent loaded on PLGA/Gel scaffold to accelerate DW healing. It was indicated that by applying Lira-loaded PLGA/Gel, 


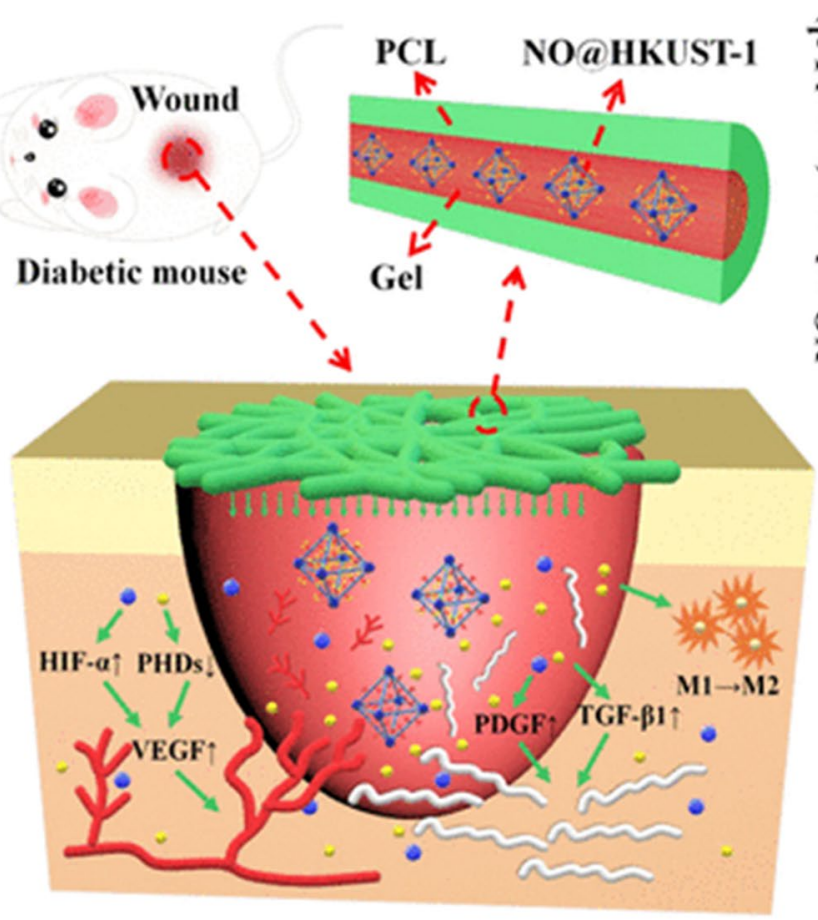

Angiogenesis \ Collagen $\mathbf{t}$ Inflammation \
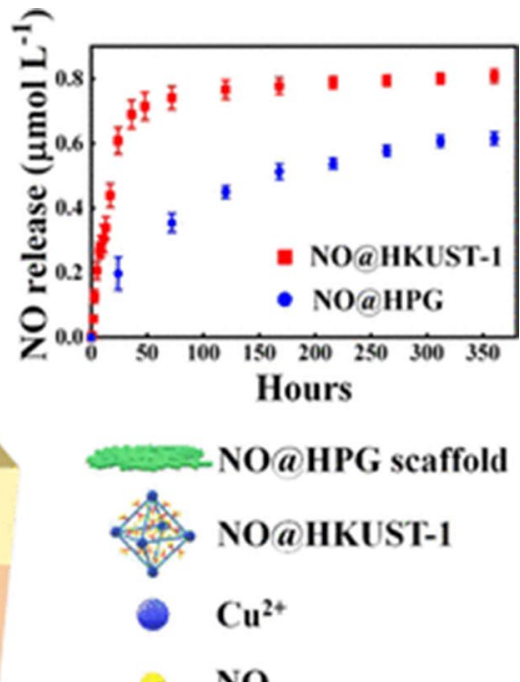

- NO

$\Psi$ Capillary

*. Macrophage

Collagen

Fig. 12 Schematic illustration of an electrospun copper-based MOF (HKUST-1) applied for the acceleration of DW healing process. Reproduced with permission from Ref. [168]

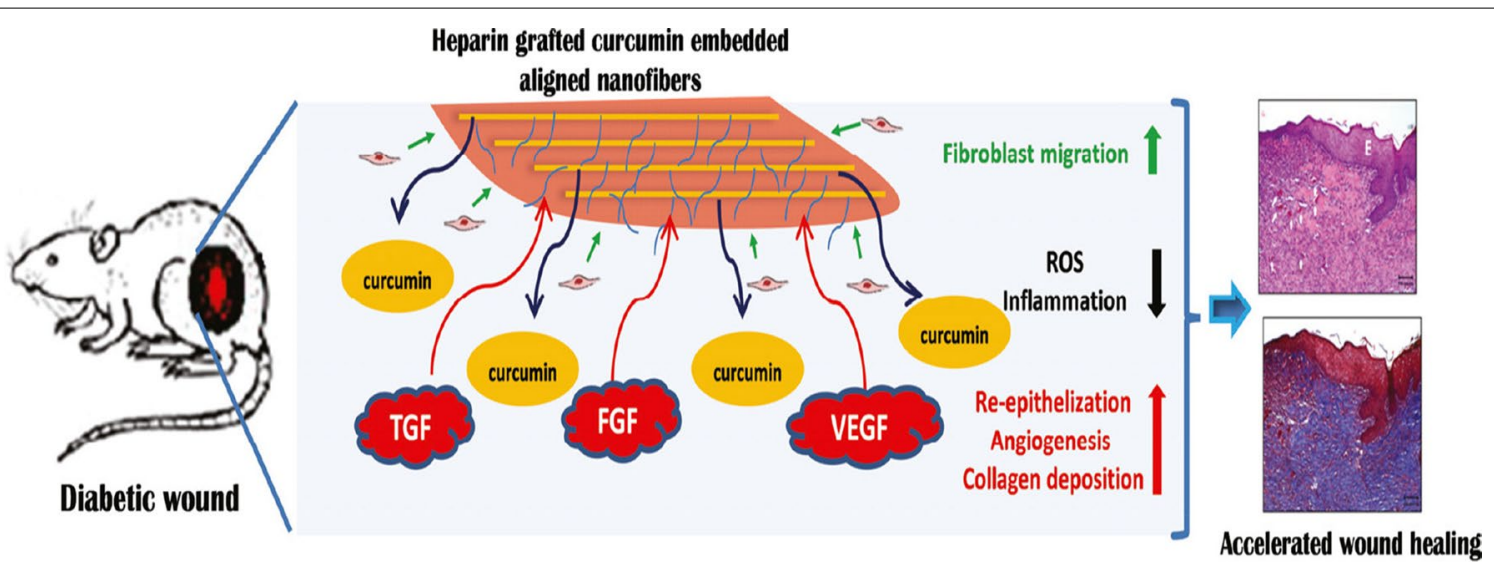

Fig. 13 Conceptual design of heparin implanted Cur embedded aligned mats. Reproduced with permission from Ref. [172]

meaningfully higher vascular density, higher collagen deposition level, and faster wound healing were achieved [173].

\section{Miscellaneous-based mats}

Pietramaggiori et al. prepared poly- $N$-acetyl glucosamine (pGlcNAc) fiber mats, and then they considered it for wound healing in the $\mathrm{db} / \mathrm{db}$ mice. The obtained mat can be potentially applied as an effective agent for complex wounds owing to its blend of hemostatic and wound healing properties [174].

Kanji et al. proposed an aminated PES NF-extended human umbilical cord blood-derived $\mathrm{CD} 34^{+}$cells (henceforth $\mathrm{CD} 34^{+}$cells) real therapy, examined in cutaneous wounds for DW healing process in mice. They offered the proof of an innovative NF-expanded $\mathrm{CD} 34^{+}$stem cell 
a

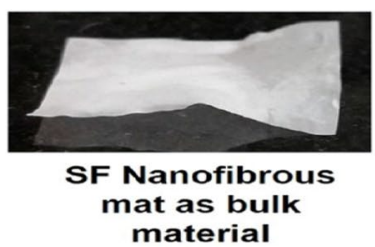

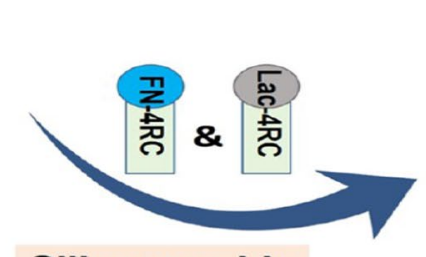

Silk assembly

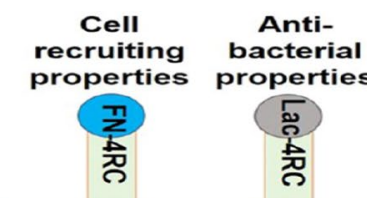

Silkworm silk fibroin bulk material

b

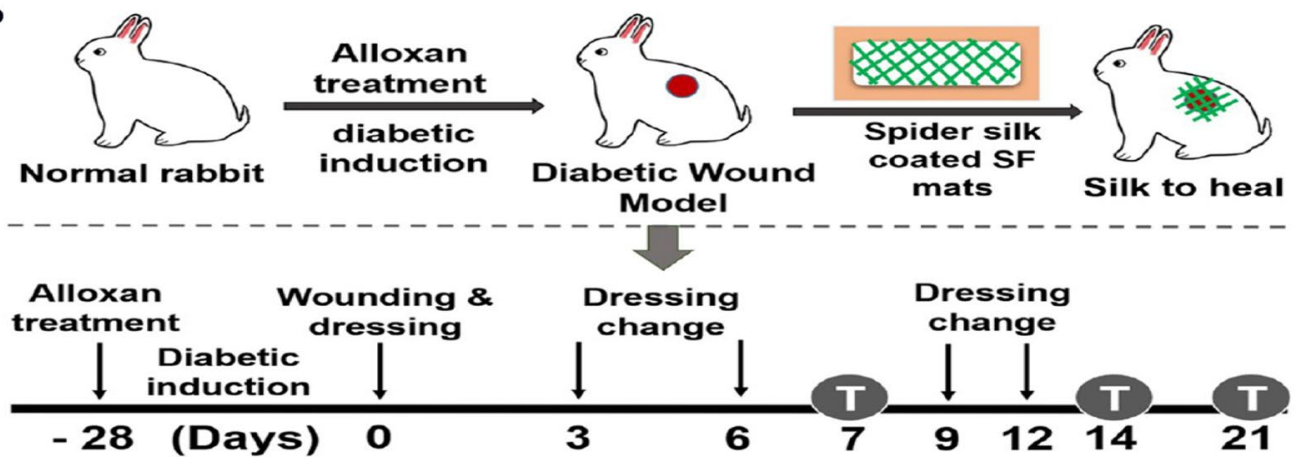

Fig. 14 Schematic representation of the experimental design describing (a) methodology to prepare bioactive silk dressings by modifying spider SF proteins on top of SF nanofibrous mats and (b) approach of acting cutaneous wounds in a diabetic rabbit model by silk mats; DM condition was found for 28 days before wounding, mats were replaced after 3 days for 12 days, and groups were accomplished on day 7, 14, and 21 as indicated by $(\mathrm{T})$ in the sketch. Reproduced with permission from Ref. [177]

healing for improving DWs by describing their cellular and molecular mechanisms [175].

In addition to antidiabetic agents, several other small molecules with varying biological characteristics were loaded into different NF scaffolds for wound dressing. In this regard, Han et al. showed that asiatic acid, an active ingredient of Centella asiatica (a Chinese medicinal herb), which have antioxidant, anti-inflammatory, and anti-bacterial properties when embedded in aligned porous PLLA electrospun fibrous scaffold could treat non-healing DWs [176].

SF derived from Antheraea assama silkworm (AaSF), coated with several recombinant spider silk fusion proteins over silk-silk connections, was employed as a bioactive NF mat for the wound healing process in diabetic rabbits (Fig. 14). The proposed system declared quick granulation tissue improvement, re-epithelialization, and well-organized matrix remodelling of wounds. Hence, the results obviously proved possible of achieved mats in earlier treatment of DWs [177]. In the case of diabetic rabbits, Elshazly et al. reported a novel formula of electrospun bioactive glass nanofibers (BGnf) containing $\mathrm{B}_{2} \mathrm{O}_{3}, \mathrm{SiO}_{2}$, and $\mathrm{CaO}$ for the improvement of oral mucosal wound regeneration. The findings indicated that obtained system can be applied as a sustainable oral cavity bioscaffold in a wet environment as well as can be applied for an immune-compromised disorder as DM [178].
Cui et al. also compared the effectiveness of topical doxycycline, an antibacterial agent, versus doxycyclineloaded PLA NF mats produced by ES technique for treatment/prevention of infection in DWs. Their results showed that doxycycline-PLA NF mats were superior to topical doxycycline to treat DWs, due to fewer side effects and better release profile [179].

Taking together, the results obtained from these studies revealed that proposed systems with different strategies are an ideal choice for scaffolds not only because of their biological characteristics but also owing to the possibility of using different therapeutic and preventive agents-loaded mats for DWs healing. Based on our observations, proposed mats were suggested as great tools with the ability to improve epidermal regeneration and re-epithelialization, promoting angiogenesis, and collagen deposition, and lessening inflammatory response. At last, it seems that antidiabetic agents and MSCs-loaded scaffolds can be a better choice for encapsulation in different mats so that we could apply for treatment of DWs, specifically chronic wounds.

Table 4 indicates several key features of above-mentioned studies. We tried to represent the most common characteristics, including the type of polymers/materials, the incorporated/modified agents, and diameter of NFs, applied cell type, and the main finding of proposed systems in this table. 


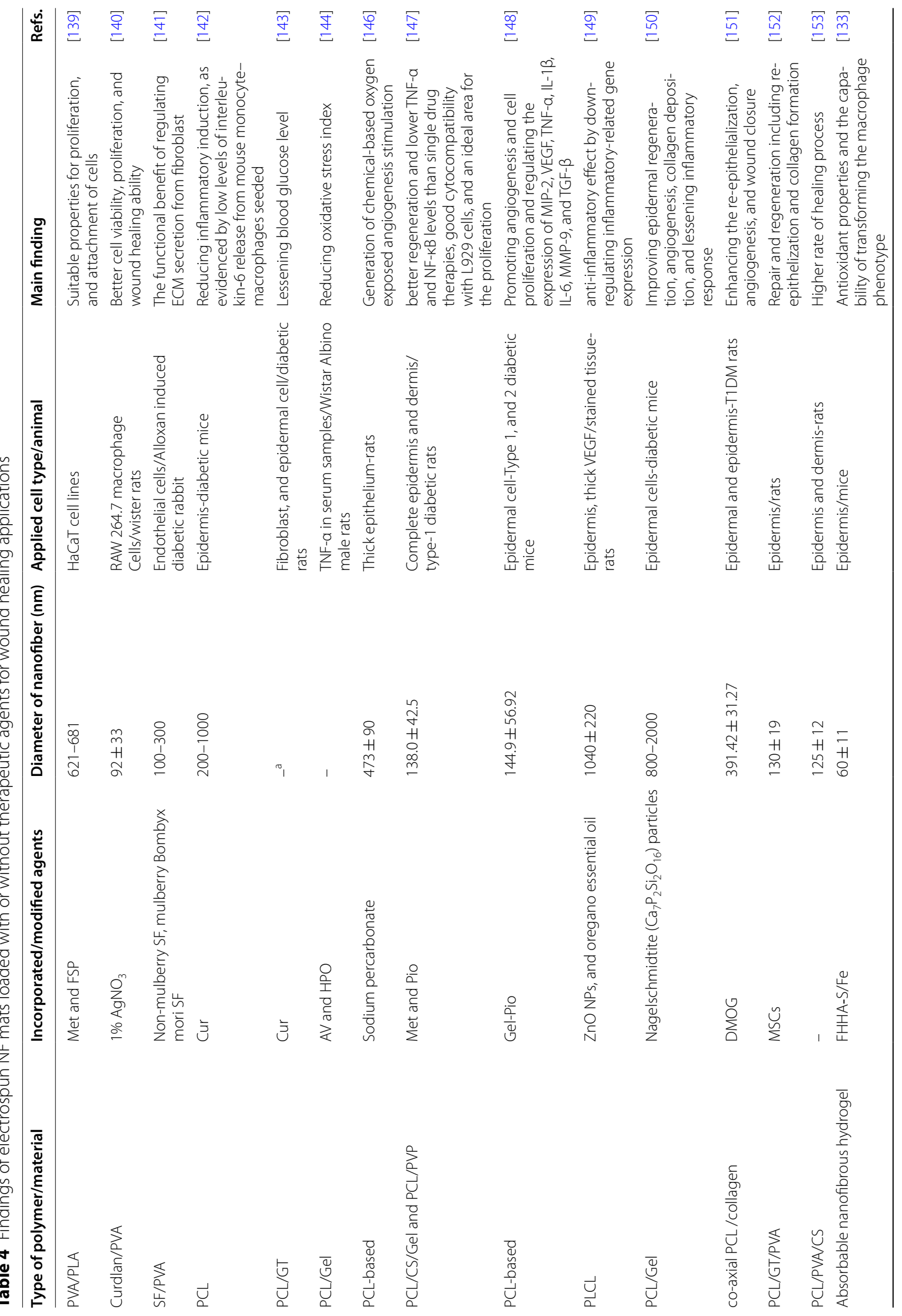




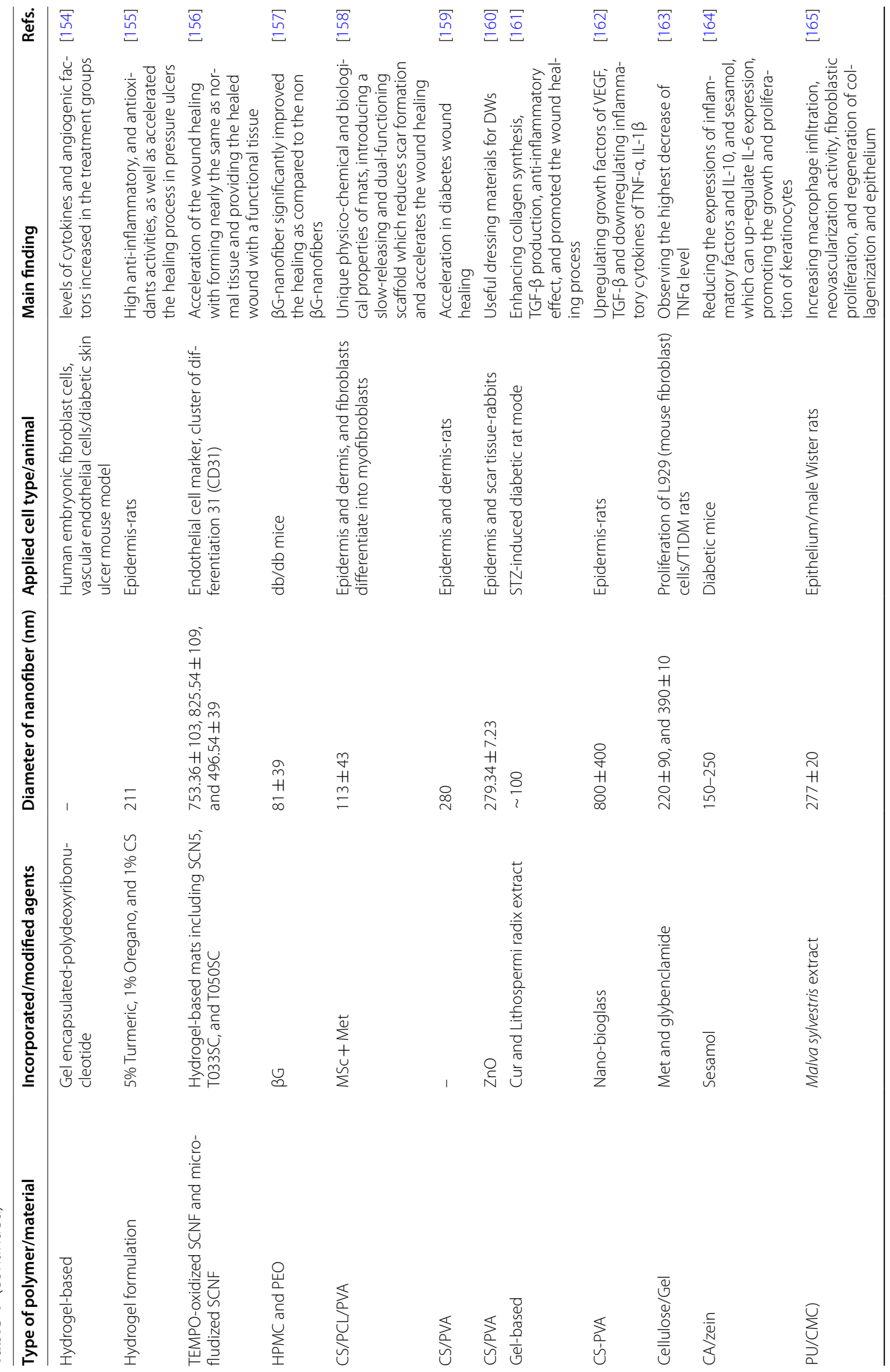




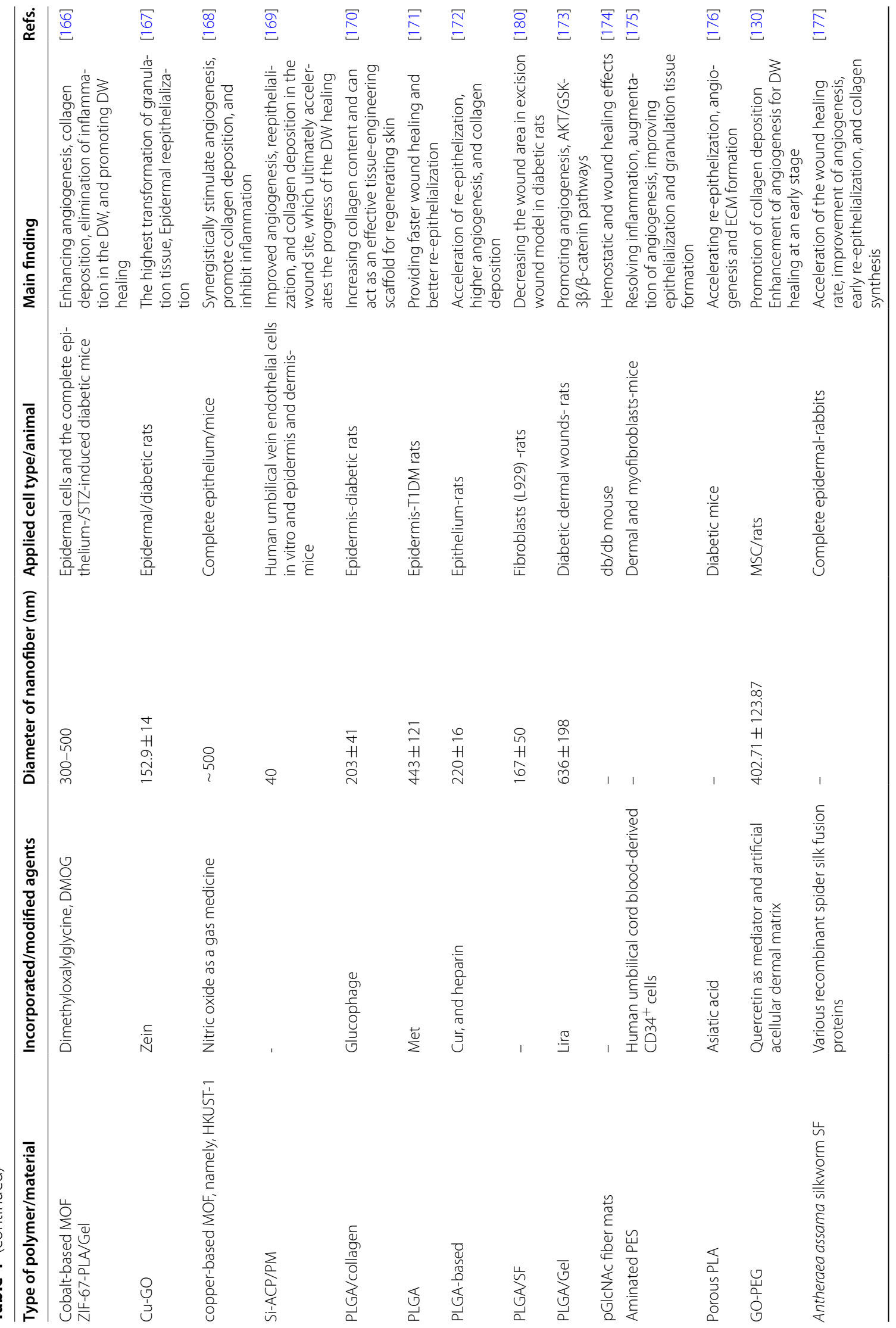




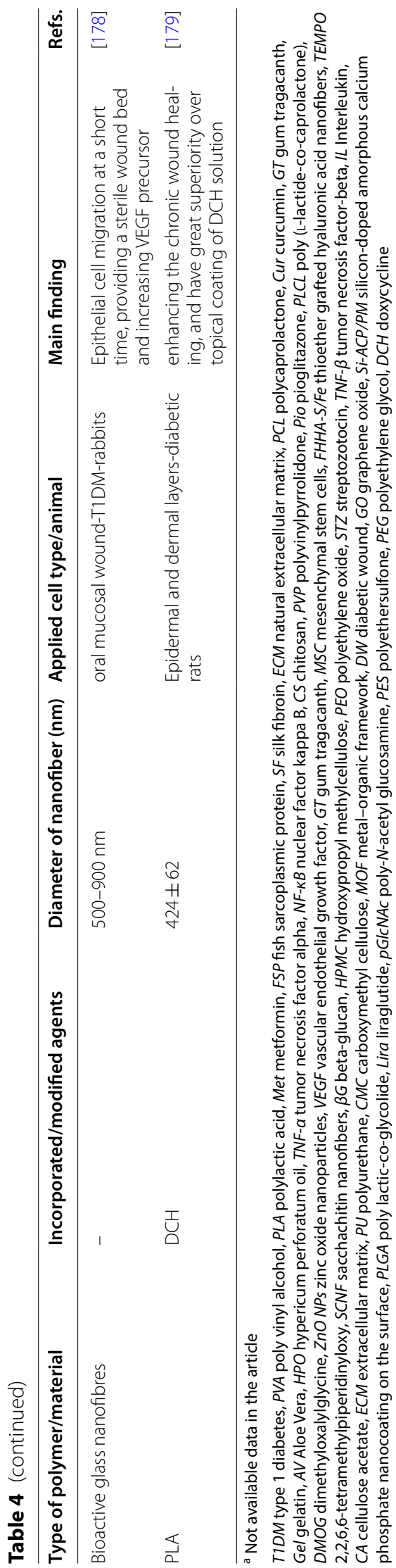




\section{Electrospun NF mats and drug delivery systems}

Despite numerous NFs in wound dressing applications, these biocompatible electrospun NFS have also been developed for drug delivery systems [168-170].In this regard, PVA NF patches loaded with linagliptin, an antidiabetic drug, were applied for sublingual administration [181]. In another example, the water solubility, drug release profile, and efficiency of repaglinide (an antidiabetic agent) for glycemic control were improved while loaded to PVA- PVP NFs [182]. Besides, Heydari-Majd et al. considered zein NFs as a delivery carrier for Barije (Ferula gummosa) essential oil (EO) which has antioxidant and antidiabetic (by inhibition of $\alpha$-glucosidase and $\alpha$-amylase enzymes) activity. Their results verified that, under the simulated gastrointestinal conditions, the release profile of Barije EO was found suitable for encapsulation using zein NFs and could consider as a novel tool for DM treatment [183]. In one study, Vildagliptin-eluting PLGA electrospun NFs was prepared as stents to treat diabetic vascular disease. The obtained membranes indicated great recovery of diabetic endothelial and reduction of smooth muscle cell (SMC) hyperplasia. Obtained results revealed that proposed stent could potentially accelerate the healing of diabetic arterial disorders [184].

It is concluded that the proposed systems in this section can be delivered in a controlled manner, and an adjustable glycemic control can be achieved via encapsulation of various antidiabetic agents in the scaffolds. Although for DM treatment, scaffolds loaded with therapeutic agents intended for oral administration could be more efficient than the topical ones, however, topical scaffolds were extensively applied due to simplicity and capability of sustained and controlled drug delivery to the wound site.

\section{Market size of advanced wound care}

The global advanced wound care market size exceeded $\$ 10.2$ billion (BN) in 2019 and is poised to raise at over $5.2 \%$ compound around growth rate (CAGR) between 2020 and 2026 (Fig. 15). The increasing prevalence of acute and chronic wounds in diabetes and obese population, as well as increasing geriatric population base that is at high risk of developing chronic wounds specifically DW, will augment the market size [185].

The strategic trends in the market are the growing consumption of NF-based wound dressing and rising demand for incorporation dressings. Incorporation dressings including natural and chemical agents, such as silver alginate, collagen hydrochloride, and silver collagen, averts infection and speeds up wound healing process. Thanks to the great preventive and therapeutic efficiency of advanced wound dressings, it is a foremost trend in the advanced wound care market.
Limitations, future perspectives, and conclusions

Even though various studies showed that electrospun NF mats play a key role in wound healing applications, ES process possesses definite limitations in elastic possibility due to its conservative setup that is typically fairly bulky and extremely dependent on a plug. The selection of suitable blend polymers and therapeutic agents has still remained the main challenge for wound dressing fabrication. Furthermore, some restrictions and limitations for islet transplant procedure are restricted by the loss of integrity and demolition of blood vessel networks as well as insufficient access to nutrients and GFs.

The wound healing process using dressings is growing faster progressively owing to an increase in the world population ( $\$ 45.5$ billion by 2024$)$. Hence, chronic wound cases also need to improve proper medication, which can effectively conquest the gentle wound healing process and hinder wound infection. Consequently, physicians, pharmacologists, biomedical engineers, and other relevant fields should research together in this path for better releasing of the wound healing process, enhanced drug efficacy, and enhanced drug delivery systems. This research review article defines the wound healing process using various nanosystems, including electrospun NFs for DWs healing. These systems, including therapeutic and preventive agents play a pivotal role to protect and improve the wound healing process specially DWs. Besides, emerging smart mats can also promote DWs healing and real-time monitoring. The assessment of the wound healing process indicates that electrospun NF mats provide better features compared to common mats in respect of cost, healing time process, and effective and sustainable drug delivery. In addition, NF-based systems typically act as non-invasive, biodegradable, biocompatible systems without notable side effects, which have been more considered in wound healing promotion while compared to the other systems. It is also believed that obtained mats can pave the route of preclinical and clinical studies in TE and regenerative medicine, exclusively wound healing process.

Blending various polymers using more effective crosslinking methods to produce enhanced scaffolds that support an optimal wound healing process was developed in recent years. As alluded to above, natural polymers, including cellulose and its derivatives, CS, hyaluronic acid, collagen, SF, and synthetic polymers including PVP, PVA, PLGA, PLA, PCL, PEG, PVP, PU were merged together with or without cross-linkers to apply for wound dressing applications. Besides, therapeutic wound dressings were inspected to powerfully deliver therapeutic and preventive agents that had earlier been revealed to promote the wound healing process, specifically DWs. A clear approach for the reduction of infection is applying 


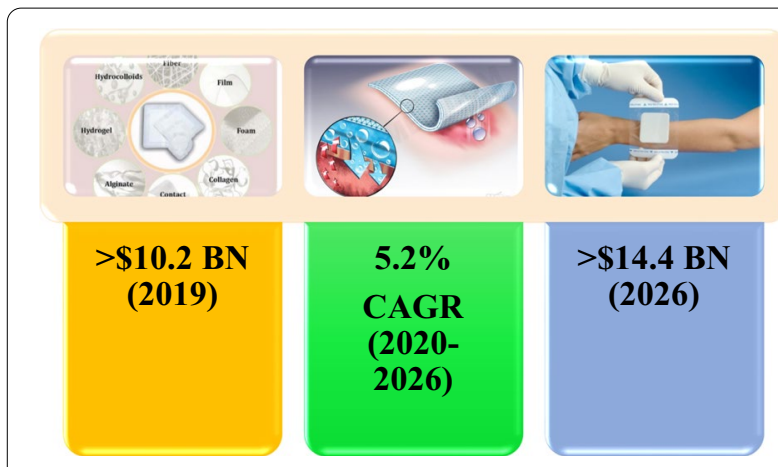

Fig. 15 The global advanced wound care market size from 2019 to 2026. BN billion, CAGR compound around growth rate

electrospun NFs loaded with antidiabetics/antimicrobial compounds, platelet-derived ingredients, MSCs, GFs, and peptides to control up-regulation of GFs and ECM secretion from fibroblast, and down-regulation of inflammatory cytokines and inflammatory-related gene expression in DWs to accelerate the healing process. Moreover, re-epithelialization, angiogenesis, wound closure, epidermal regeneration, and collagen formation have been promoted in most cases. Regarding the encapsulation of natural extracts, several studies displayed notable potential in the considerable healing of DWs; however, these outcomes do not recommend a fruitful choice since the efficiency of herbal extract, adjustment of their impact has remained as key challenges. Hence, relevant research studies will definitely focus on developing more potent and less costly biocompatible and biodegradable therapeutic mats that provide great healing to DWs to promote patient treatment and quality of life. We hope that therapeutic and preventive electrospun NF mats have opened a door for exploring novel wound healing processes to be applied in DWs, as well as many other expectations.

\footnotetext{
Abbreviations

3D: Three dimensional; ADMSC: Adipose-derived mesenchymal stem cell; AV: Aloe vera; AaSF: Antheraea assama silkworm; bFGF: Basic fibroblast growth factor; $\beta$ G: Beta-glucan; BC: Bacterial cellulose; BGnf: Bioactive glass NFs; CA: Cellulose acetate; CS: Chitosan; CTGF: Connective tissue growth factor; CNC: Cellulose nanocrystal; Cur: Curcumin; CMC: Carboxymethyl cellulose; DM: Diabetes mellitus; DW: Diabetic wound; DMOG: Dimethyloxalylglycine; PDRN: Polydeoxyribonucleotide; ECM: Extracellular matrix; ES: Electrospinning; EGF: Endothelial growth factor; EnSC: Endometrial stem cell; NF: Nanofiber; FDA: Food and Drug Administration; FGF2: Fibroblast growth factor 2; FHHA-S/Fe: Thioether grafted hyaluronic acid nanofibers; FSP: Fish sarcoplasmic protein; GF: Growth factors; Gel: Gelatin; GO: Graphene oxide; GN: Gelation nanoparticles; GT: Gum tragacanth; HA: Hyaluronic acid; HBPA: Heparin-binding peptide amphiphile; hiPSCs: Human-induced pluripotent stem cells; HPO: Hypericum perforatum oil; HE: Human embryonic; IPCs: Insulin producing cells; IT: Islet transplantation; iPSCs: Induced pluripotent stem cell; LPEI: Linear polyethyleneimine; Lira: Liraglutide; MSC: Mesenchymal stem cells; Met: Metformin; MOF: Metal-organic framework; NP: Nanoparticle; nBG-TFM: Nanobioglass integrated CS-PVA trilayer electrospun NF membrane; PCL: Polycaprolactone; PM: PuraMatrix ${ }^{\mathrm{TM}}$; PM-Isol: PM-insulin sol; PVA: Poly vinyl alcohol; PLA: Polylactic
}

acid; PLGA: Poly lactic-co-glycolide; PEG: Polyethylene glycol; PES: Polyethersulfone; PHBV: Poly 3-hydroxybutyrate-co-3-hydroxyvalerate; PAN: PolyacryIonitrile; phEGF: Plasmid human epidermal growth factor; PELA: Poly(ethylene glycol)-poly(DL-lactide); PDGF: Platelet-derived growth factor; PA: Peptide amphiphiles; PHBV: Poly 3-hydroxybutyrate-co-3-hydroxyvalerate; PDRN: Polydeoxyribonucleotide; PEO: Poly (ethylene oxide); PU: Polyurethane; pGICNAc: Poly-N-acetyl glucosamine; PVP: Polyvinylpyrrolidone; Pio: Pioglitazone; PLCL: Poly (L-lactide-co-caprolactone); SF: Silk fibroin; SCNF: Sacchachitin nanofibers; Si-ACP/PM: Silicon-doped amorphous calcium phosphate nanocoating; sNAG: Surface poly-N-acetyl glucosamine; TE: Tissue engineering; VEGF: Vascular endothelial growth factor; ZnO: Zinc oxide.

\section{Acknowledgements}

This work was nonfinancially supported by Endocrinology and Metabolism Research Institute, Tehran University of Medical Sciences.

\section{Authors' contributions}

HM Conceptualization, Investigation, Methodology, Design, Writing-review and editing. KK: Conceptualization, Investigation, Methodology, Design, Writing-review and editing. SMSJ: Investigation, Methodology, Design, Writing-review and editing. HB: Investigation, Methodology, Writing-review and editing. MD: Investigation, Writing-review. NK: Methodology Writing-review and editing FS: Methodology, Writing-review and editing. All authors read and approved the final manuscript.

Funding

Private funds were applied to carry out this study.

Availability of data and materials

Not Applicable.

\section{Declarations}

Ethics approval and consent to participate

Not applicable.

\section{Consent for publication}

All the authors have approved this review article and agreed with submission.

\section{Competing interests}

The authors declare that they have no competing interests.

\section{Author details}

${ }^{1}$ Nano Drug Delivery Research Center, Health Technology Institute, Kermanshah University of Medical Sciences, Kermanshah, Iran. ${ }^{2}$ Medical Nanotechnology and Tissue Engineering Research Center, Shahid Beheshti University of Medical Sciences, Tehran, Iran. ${ }^{3}$ Department of Tissue Engineering and Applied Cell Sciences, School of Advanced Technologies in Medicine, Shahid Beheshti University of Medical Sciences, Tehran, Iran. ${ }^{4}$ Cell Therapy and Regenerative Medicine Research Center, Endocrinology and Metabolism Molecular-Cellular Sciences Institute, Tehran University of Medical Sciences, 1411713137 Tehran, Iran. ${ }^{5}$ Department of Medical Nanotechnology, Applied Biophotonics Research Center, Science and Research Branch, Islamic Azad University, 1477893855 Tehran, Iran. ${ }^{6}$ Research and Development Team, Evolution Wound Dressing (EWD) Startup Co., Tehran, Iran. ${ }^{7}$ Elderly Health Research Center, Endocrinology and Metabolism Population Sciences Institute, Tehran University of Medical Sciences, 1411713137 Tehran, Iran. ${ }^{8}$ Endocrinology and Metabolism Research Center, Endocrinology and Metabolism Clinical Sciences Institute, Tehran University of Medical Sciences, 1411713137 Tehran, Iran.

Received: 23 July 2021 Accepted: 28 September 2021

Published online: 12 October 2021

References

1. Mo R, Jiang T, Di J, Tai W, Gu Z. Emerging micro- and nanotechnology based synthetic approaches for insulin delivery. Chem Soc Rev. 2014;43:3595. https://doi.org/10.1039/C3CS60436E. 
2. Standards of medical care in diabetes-2012. American Diabetes Association 2012;35(Suppl 1):S11-63. www.ngsp.org/.

3. Federation ID. IDF Diabetes Atlas-2019. International Diabetes Federation. Brussels, Belgium: 2019.

4. Ng LC, Gupta M. Transdermal drug delivery systems in diabetes management: a review. Asian J Pharm Sci. 2020;15:13-25. https://doi.org/ 10.1016/j.ajps.2019.04.006.

5. Harding JL, Pavkov ME, Magliano DJ, Shaw JE, Gregg EW. Global trends in diabetes complications: a review of current evidence. Diabetologia. 2019;62:3-16. https://doi.org/10.1007/s00125-018-4711-2.

6. Zhang Y, Yu J, Kahkoska AR, Wang J, Buse JB, Gu Z. Advances in transdermal insulin delivery. Adv Drug Deliv Rev. 2019;139:51-70. https:// doi.org/10.1016/j.addr.2018.12.006.

7. Heinemann L, Jacques Y. Oral insulin and buccal insulin: a critical reappraisal. J Diabetes Sci Technol. 2009;3:568-84. https://doi.org/10.1177/ 193229680900300323.

8. Cernea S, Raz I. Insulin therapy: future perspectives. Am J Ther. 2020;27:e121-32. https://doi.org/10.1097/MJT.0000000000001076.

9. Henkin RI. Inhaled insulin -intrapulmonary, intranasal, and other routes of administration: mechanisms of action. Nutr. 2010;26:33-9. https://doi.org/10.1016/j.nut.2009.08.001.

10. Fonte P, Araújo F, Reis S, Sarmento B. Oral insulin delivery: how far are we? J Diabetes Sci Technol. 2013;7:520-31. https://doi.org/10.1177/ 193229681300700228.

11. Iyer $\mathrm{H}$, Khedkar A, Verma M. Oral insulin—a review of current status. Diabetes Obes Metab. 2010;12:179-85. https://doi.org/10.1111/j.14631326.2009.01150.x.

12. Wong CY, Martinez J, Dass CR. Oral delivery of insulin for treatment of diabetes: status quo, challenges and opportunities. J Pharm Pharmacol. 2016;68:1093-108. https://doi.org/10.1111/jphp.12607.

13. Cernea S, Raz I. Noninjectable methods of insulin administration. Drugs Today. 2006;42:405. https://doi.org/10.1358/dot.2006.42.6. 985632.

14. Chen J, Hu L, Yang G, Hu Q. Current therapeutic strategy in the nasal delivery of insulin: recent advances and future directions. Curr Pharm Biotechnol. 2018;19:400-15. https://doi.org/10.2174/1389201019 666180619145429.

15. Sousa F, Castro P, Fonte P, Sarmento B. How to overcome the limitations of current insulin administration with new non-invasive delivery systems. Ther Deliv. 2015;6:83-94. https://doi.org/10.4155/tde.14.82.

16. Easa N, Alany RG, Carew M, Vangala A. A review of non-invasive insulin delivery systems for diabetes therapy in clinical trials over the past decade. Drug Discov Today. 2019;24:440-51. https://doi.org/10.1016/j. drudis.2018.11.010.

17. Sharma M. Transdermal and intravenous nano drug delivery systems: present and future. In: Applications of targeted nano drugs and delivery systems. 2019;499-550. https://doi.org/10.1016/B978-0-12-8140291.00018-1.

18. Disanto RM, Subramanian V, Gu Z. Recent advances in nanotechnology for diabetes treatment. Wiley Interdiscip Rev Nanomed Nanobiotechnol. 2015;7:548-64. https://doi.org/10.1002/wnan.1329.

19. Primavera R, Kevadiya BD, Swaminathan G, Wilson RJ, De Pascale A, Decuzzi P, et al. Emerging Nano- and micro-technologies used in the treatment of type-1 diabetes. Nanomaterials. 2020;10:789. https://doi. org/10.3390/nano10040789.

20. Souto EB, Souto SB, Campos JR, Severino P, Pashirova TN, Zakharova LY, et al. Nanoparticle delivery systems in the treatment of diabetes complications. Molecules. 2019;24:4209. https://doi.org/10.3390/molec ules24234209.

21. Wang X, Ding B, Yu J, Wang M. Engineering biomimetic superhydrophobic surfaces of electrospun nanomaterials. Nano Today. 2011;6:510-30. https://doi.org/10.1016/j.nantod.2011.08.004.

22. Rao GK, Kurakula M, Yadav KS. Application of electrospun materials in gene delivery. Electrospun materials and their allied applications. Wiley. 2020:265-306. https://doi.org/10.1002/9781119655039.ch10.

23. Augustine R, Zahid AA, Hasan A, Wang M, Webster TJ. CTGF loaded electrospun dual porous core-shell membrane for diabetic wound healing. Int J Nanomed. 2019;14:8573-88. https://doi.org/10.2147/IJN. S224047.

24. Sagitha P, Reshmi CR, Sundaran SP, Sujith A. Recent advances in postmodification strategies of polymeric electrospun membranes. Eur
Polym J. 2018;105:227-49. https://doi.org/10.1016/j.eurpolymj.2018.05. 033.

25. Ji W, Yang F, van den Beucken JJJP, Bian Z, Fan M, Chen Z, et al. Fibrous scaffolds loaded with protein prepared by blend or coaxial electrospinning. Acta Biomater. 2010;6:4199-207. https://doi.org/10.1016/j. actbio.2010.05.025.

26. Nicolas J, Magli S, Rabbachin L, Sampaolesi S, Nicotra F, Russo L. 3D Extracellular matrix mimics: fundamental concepts and role of materials chemistry to influence stem cell fate. Biomacromol. 2020;21:196894. https://doi.org/10.1021/acs.biomac.0c00045.

27. Hoveizi E, Tavakol S, Shirian S, Sanamiri K. Electrospun nanofibers for diabetes: tissue engineering and cell-based therapies. Stem Cell Res Ther. 2019;14:152-68. https://doi.org/10.3390/nano11010021.

28. Bahmad HF, Poppiti R, Alexis J. Nanotherapeutic approach to treat diabetic foot ulcers using tissue-engineered nanofiber skin substitutes: a review. Diabetes Metab Syndr Clin Res Rev. 2021;15:487-91. https:// doi.org/10.1016/j.dsx.2021.02.025.

29. Son YJ, Kim WJ, Yoo HS. Therapeutic applications of electrospun nanofibers for drug delivery systems. Arch Pharmacal Res. 2014;37:6978. https://doi.org/10.1007/s12272-013-0284-2.

30. Sahu DK, Ghosh G, Rath G. Nanofibers in drug delivery. Nanopharmaceutical advanced delivery systems. Wiley 2021:99-123. https://doi. org/10.1002/9781119711698.ch5.

31. Wang J, Xu J. Effects of topical insulin on wound healing: a review of animal and human evidences. Diabet Metab Synd Ob. 2020;13:719-27. https://doi.org/10.2147/DMSO.S237294.

32. Hrynyk M, Neufeld RJ. Insulin and wound healing. Burns J Int Soc Burn Injuries. 2014;40:1433-46. https://doi.org/10.1016/j.burns.2014.03.020.

33. Ji W, Sun Y, Yang F, van den Beucken JJJP, Fan M, Chen Z, et al. Bioactive electrospun scaffolds delivering growth factors and genes for tissue engineering applications. Pharm Res. 2011;28:1259-72. https://doi.org/ 10.1007/s1 1095-010-0320-6.

34. Lee $\mathrm{S}$, Jin $\mathrm{G}$, Jang J-H. Electrospun nanofibers as versatile interfaces for efficient gene delivery. J Biol Eng. 2014;8:30. https://doi.org/10.1186/ 1754-1611-8-30.

35. Shah SA, Sohail M, Khan S, Minhas MU, de Matas M, Sikstone V, et al. Biopolymer-based biomaterials for accelerated diabetic wound healing: a critical review. Int J Biol Macromol. 2019;139:975-93. https://doi. org/10.1016/j.jijbiomac.2019.08.007.

36. Agnes Mary S, Giri Dev VR. Electrospun herbal nanofibrous wound dressings for skin tissue engineering. J Text Inst. 2015;106:886-95. https://doi.org/10.1080/00405000.2014.951247.

37. Nishimura A, Hayakawa T, Yamamoto Y, Hamori M, Tabata K, Seto K, et al. Controlled release of insulin from self-assembling nanofiber hydrogel, PuraMatrix ${ }^{\mathrm{TM}}$ : application for the subcutaneous injection in rats. Eur J Pharm Sci. 2012;45:1-7. https://doi.org/10.1016/j.ejps.2011. 10.013.

38. Kalva SN, Augustine R, Al Mamun A, Dalvi YB, Vijay N, Hasan A. Active agents loaded extracellular matrix mimetic electrospun membranes for wound healing applications. J Drug Deliv Sci Technol. 2021;63: 102500. https://doi.org/10.1016/j.jddst.2021.102500.

39. Madhukiran D, Jha A, Kumar M, Ajmal G, Bonde GV, Mishra B. Electrospun nanofiber-based drug delivery platform: advances in diabetic foot ulcer management. Expert Opin Drug Deliv. 2021;18:25-42. https://doi.org/10.1080/17425247.2021.1823966.

40. Amer LD, Mahoney MJ, Bryant SJ. Tissue engineering approaches to cell-based type 1 diabetes therapy. Tissue Eng Part B Rev. 2014;20:45567. https://doi.org/10.1089/ten.teb.2013.0462.

41. Burger $\mathrm{C}, \mathrm{Hsiao}$ BS, Chu B. Nanofibrous materials and their applications. Annu Rev Mater Res. 2006;36:333-68. https://doi.org/10.1146/annurev. matsci.36.011205.123537.

42. Alghoraibi I, Alomari S. Different methods for nanofiber design and fabrication. In: Handbook of nanofibers. Springer International Publishing; 2018:1-46. https://doi.org/10.1007/978-3-319-42789-8_11-2.

43. Rasouli R, Barhoum A, Bechelany M, Dufresne A. Nanofibers for biomedical and healthcare applications. Macromol Biosci. 2019;19:1800256. https://doi.org/10.1002/mabi.201800256.

44. Xue J, Wu T, Dai Y, Xia Y. Electrospinning and electrospun nanofibers: methods, materials, and applications. Chem Rev. 2019;119:5298-415. https://doi.org/10.1021/acs.chemrev.8b00593. 
45. Bhardwaj N, Kundu SC. Electrospinning: a fascinating fiber fabrication technique. Biotechnol Adv. 2010;28:325-47. https://doi.org/10.1016/j. biotechadv.2010.01.004.

46. Su Z, Ding J, Wei G. Electrospinning: a facile technique for fabricating polymeric nanofibers doped with carbon nanotubes and metallic nanoparticles for sensor applications. RSC Adv. 2014;4:52598-610. https://doi.org/10.1039/C4RA07848A.

47. Khajavi R, Abbasipour M. Controlling nanofiber morphology by the electrospinning process. Electrospun Nanofibers. 2017:109-23. https:// doi.org/10.1016/B978-0-08-100907-9.00005-2.

48. Zahmatkeshan M, Adel M, Bahrami S, Esmaeili F, Rezayat SM, Saeedi Y, et al. Polymer based nanofibers: preparation, fabrication, and applications. In: Handbook of nanofibers. Springer International Publishing; 2018:1-47. https://doi.org/10.1007/978-3-319-53655-2_29.

49. Agrahari $\vee$, Agrahari $\vee$, Meng J, Mitra AK. Electrospun nanofibers in drug delivery: fabrication, advances, and biomedical applications. In: Emerging nanotechnologies for diagnostics, drug delivery and medical devices. 2017:189-215. https://doi.org/10.1016/B978-0-323-429788.00009-7.

50. Haider A, Haider S, Kang IK. A comprehensive review summarizing the effect of electrospinning parameters and potential applications of nanofibers in biomedical and biotechnology. Arab J Chem. 2018;11:1165-88. https://doi.org/10.1016/j.arabjc.2015.11.015.

51. Yuan $\mathrm{H}$, Zhou Q, Zhang Y. Improving fiber alignment during electrospinning. In: Electrospun Nanofibers. 2017:125-47. https://doi.org/10. 1016/B978-0-08-100907-9.00006-4.

52. Nayak R, Padhye R, Arnold L. Melt-electrospinning of nanofibers. In: Electrospun Nanofibers. Elsevier; 2017:11-40. https://doi.org/10.1016/ B978-0-08-100907-9.00002-7.

53. Gorji M, Bagherzadeh R, Fashandi H. Electrospun nanofibers in protective clothing. In: Electrospun Nanofibers. Elsevier; 2017:571-98. https:// doi.org/10.1016/B978-0-08-100907-9.00021-0.

54. Kamble P, Sadarani B, Majumdar A, Bhullar S. Nanofiber based drug delivery systems for skin: a promising therapeutic approach. J Drug Deliv Sci Technol. 2017;41:124-33. https://doi.org/10.1016/j.jddst.2017. 07.003 .

55. Liu Y, Zhou S, Gao Y, Zhai Y. Electrospun nanofibers as a wound dressing for treating diabetic foot ulcer. Asian J Pharm Sci. 2019;14:130-43. https://doi.org/10.1016/j.ajps.2018.04.004.

56. Baji A, Mai YW, Wong SC, Abtahi M, Chen P. Electrospinning of polymer nanofibers: effects on oriented morphology, structures and tensile properties. Compos Sci Technol. 2010;70:703-18. https://doi.org/10. 1016/j.compscitech.2010.01.010.

57. Soliman S, Sant S, Nichol JW, Khabiry M, Traversa E, Khademhosseini A. Controlling the porosity of fibrous scaffolds by modulating the fiber diameter and packing density. J Biomed Mater Res A. 2011;96:566-74. https://doi.org/10.1002/jbm.a.33010.

58. Loh QL, Choong C. Three-dimensional scaffolds for tissue engineering applications: role of porosity and pore size. Tissue Eng Part B Rev. 2013;19:485-502. https://doi.org/10.1089/ten.teb.2012.0437.

59. Singh R, Goel S, Sharma PK, Agarwal A. Hydrogel as a novel drug delivery system: recent advancements and patents. Curr Nanosci. 2020;17:14-25. https://doi.org/10.2174/1573413716999200626211915.

60. Ahmed EM. Hydrogel: preparation, characterization, and applications: a review. J Adv Res. 2015;6:105-21. https://doi.org/10.1016/j.jare.2013. 07.006 .

61. Han S, Nie K, Li J, Sun Q, Wang X, Li X, et al. 3D Electrospun nanofiberbased scaffolds: from preparations and properties to tissue regeneration applications. Stem Cells Int. 2021:1-22. https://doi.org/10.1155/ 2021/8790143.

62. Annabi N, Nichol JW, Zhong X, Ji C, Koshy S, Khademhosseini A, et al. Controlling the porosity and microarchitecture of hydrogels for tissue engineering. Tissue Eng Part B Rev. 2010;16:371-83. https://doi.org/10. 1089/ten.teb.2009.0639.

63. Ghosh T, Das T, Purwar R. Review of electrospun hydrogel nanofiber system: synthesis, properties and applications. Polym Eng Sci. 2021;61:1887-911. https://doi.org/10.1002/pen.25709.

64. Hadjiargyrou M, Chiu JB. Enhanced composite electrospun nanofiber scaffolds for use in drug delivery. Expert Opin Drug Deliv. 2008;5:1093106. https://doi.org/10.1517/17425247.5.10.1093.
65. Frantz C, Stewart KM, Weaver VM. The extracellular matrix at a glance. J Cell Sci. 2010;123:4195-200. https://doi.org/10.1242/jcs.023820.

66. Rozario T, DeSimone DW. The extracellular matrix in development and morphogenesis: a dynamic view. Dev Biol. 2010;341:126-40. https:// doi.org/10.1016/j.ydbio.2009.10.026.

67. Barnes CP, Sell SA, Boland ED, Simpson DG, Bowlin GL. Nanofiber technology: designing the next generation of tissue engineering scaffolds. Adv Drug Deliv Rev. 2007;59:1413-33. https://doi.org/10.1016/j.addr. 2007.04.022.

68. DeFrates KG, Moore R, Borgesi J, Lin G, Mulderig T, Beachley V, et al. Protein-based fiber materials in medicine: a review. Nanomaterials. 2018;8:457. https://doi.org/10.3390/nano8070457.

69. Samadian H, Maleki H, Fathollahi A, Salehi M, Gholizadeh S, Derakhshankhah $\mathrm{H}$, et al. Naturally occurring biological macromoleculesbased hydrogels: potential biomaterials for peripheral nerve regeneration. Int J Biol Macromol. 2020;154:795-817. https://doi.org/10.1016/j. ijbiomac.2020.03.155.

70. Hoveizi E, Khodadadi S, Tavakol S, Karima O, Nasiri-Khalili MA. Small molecules differentiate definitive endoderm from human induced pluripotent stem cells on PCL scaffold. Appl Biochem. 2014;173:172736. https://doi.org/10.1007/s12010-014-0960-9.

71. Khoshnevisan K, Maleki H, Samadian H, Shahsavari S, Sarrafzadeh MH, Larijani B, et al. Cellulose acetate electrospun nanofibers for drug delivery systems: applications and recent advances. Carbohydr Polym. 2018;198:131-41. https://doi.org/10.1016/j.carbpol.2018.06.072.

72. Khoshnevisan K, Maleki H, Samadian H, Doostan M, Khorramizadeh MR. Antibacterial and antioxidant assessment of cellulose acetate/ polycaprolactone nanofibrous mats impregnated with propolis. Int J Biol Macromol. 2019;140:1260-8. https://doi.org/10.1016/j.ijbiomac. 2019.08.207.

73. Baharifar $\mathrm{H}$, Honarvarfard E, Haji Malek-kheili M, Maleki H, Barkhi M, Ghasemzadeh A, et al. The potentials and applications of cellulose acetate in biosensor technology. Nanomed Res J. 2017;2:216-23. https://doi.org/10.22034/NMRJ.2017.04.002.

74. Konwarh R, Karak N, Misra M. Electrospun cellulose acetate nanofibers: the present status and gamut of biotechnological applications. Biotechnol Adv. 2013;31:421-37. https://doi.org/10.1016/j.biotechadv. 2013.01.002.

75. Doostan M, Maleki H, Doostan M, Khoshnevisan K, Faridi-Majidi R, Arkan E. Effective antibacterial electrospun cellulose acetate nanofibrous patches containing chitosan/erythromycin nanoparticles. Int J Biol Macromol. 2021;168:464-73. https://doi.org/10.1016/j.ijbiomac. 2020.11.174.

76. Garg T, Rath G, Goyal AK. Biomaterials-based nanofiber scaffold: targeted and controlled carrier for cell and drug delivery. J Drug Target. 2015;23:202-21. https://doi.org/10.3109/1061186X.2014.992899.

77. Maleki H, Hosseini Najafabadi MR, Webster TJ, Hadjighassem MR, Sadroddiny E, Ghanbari H, et al. Effect of Paclitaxel/etoposide co-loaded polymeric nanoparticles on tumor size and survival rate in a rat model of glioblastoma. Int J Pharm. 2021;604: 120722. https://doi.org/10. 1016/j.jpharm.2021.120722.

78. Cruz-Pineda WD, Parra-Rojas I, Rodríguez-Ruíz HA, Illades-Aguiar B, Matia-García I, Garibay-Cerdenares OL. The regulatory role of insulin in energy metabolism and leukocyte functions. J Leukoc Biol. 2021. https://doi.org/10.1002/JLB.2RU1220-847R.

79. Tundo GR, Sbardella D, Ciaccio C, Grasso G, Gioia M, Coletta A, et al. Multiple functions of insulin-degrading enzyme: a metabolic crosslight? Crit Rev Biochem Mol Biol. 2017;52:554-82. https://doi.org/ 10.1080/10409238.2017.1337707.

80. Hu Q, Luo Y. Recent advances of polysaccharide-based nanoparticles for oral insulin delivery. Int J Biol Macromol. 2018;120:775-82. https:// doi.org/10.1016/j.ijbiomac.2018.08.152.

81. Banerjee A, Wong J, Gogoi R, Brown T, Mitragotri S. Intestinal micropatches for oral insulin delivery. J Drug Target. 2017;25:608-15. https:// doi.org/10.1080/1061186X.2017.1300664.

82. Gómez-Guillén MC, Montero MP. Enhancement of oral bioavailability of natural compounds and probiotics by mucoadhesive tailored biopolymer-based nanoparticles: a review. Food Hydrocoll. 2021;118: 106772. https://doi.org/10.1016/j.foodhyd.2021.106772. 
83. Nur M, Vasiljevic T. Can natural polymers assist in delivering insulin orally? Int J Biol Macromol. 2017;103:889-901. https://doi.org/10. 1016/j.ijbiomac.2017.05.138.

84. Perry SL, McClements DJ. Recent advances in encapsulation, protection, and oral delivery of bioactive proteins and peptides using colloidal systems. Molecules. 2020;25:1161. https://doi.org/10.3390/molec ules25051161.

85. Yan $\mathrm{K}, \mathrm{Xu}$ F, Ni Y, Yao K, Zhong W, Chen Y, et al. Electrodeposition of poly (vinyl alcohol-co-ethylene) nanofiber reinforced chitosan nanocomposite film for electrochemically programmed release of protein. Polymer. 2020;193: 122338. https://doi.org/10.1016/j.polymer.2020. 122338.

86. Haider A, Gupta K, Kang I-K. PLGA/nHA hybrid nanofiber scaffold as a nanocargo carrier of insulin for accelerating bone tissue regeneration. Nanoscale Res Lett. 2014;9:314. https://doi.org/10.1186/ 1556-276X-9-314.

87. Lee C-H, Hung K-C, Hsieh M-J, Chang S-H, Juang J-H, Hsieh I-C, et al. Core-shell insulin-loaded nanofibrous scaffolds for repairing diabetic wounds. Nanomed Nanotechnol Biol Med. 2020;24:102123. https:// doi.org/10.1016/j.nano.2019.102123.

88. Stephansen K, García-Díaz M, Jessen F, Chronakis IS, Nielsen HM. Bioactive protein-based nanofibers interact with intestinal biological components resulting in transepithelial permeation of a therapeutic protein. Int J Pharm. 2015;495:58-66. https://doi.org/10.1016/j.jpharm. 2015.08.076.

89. Sharma A, Gupta A, Rath G, Goyal A, Mathur RB, Dhakate SR. Electrospun composite nanofiber-based transmucosal patch for anti-diabetic drug delivery. J Mater Chem B. 2013;1:3410-8. https://doi.org/10.1039/ C3TB20487A.

90. Lancina MG, Shankar RK, Yang H. Chitosan nanofibers for transbuccal insulin delivery. J Biomed Mater Res A. 2017;105:1252-9. https://doi. org/10.1002/jbm.a.35984.

91. Senturk B, Mercan S, Delibasi T, Guler MO, Tekinay AB. Angiogenic peptide nanofibers improve wound healing in STZ-induced diabetic rats. ACS Biomater Sci Eng. 2016;2:1180-9. https://doi.org/10.1021/ acsbiomaterials.6b00238.

92. Stendahl JC, Wang L-J, Chow LW, Kaufman DB, Stupp SI. Growth factor delivery from self-assembling nanofibers to facilitate islet transplantation. Transplantation. 2008;86:478-81. https://doi.org/10.1097/TP. Ob013e3181806d9d.

93. Liu J, Liu S, Zhang L, Cheng J, Lu Y. Sustained release of hepatocyte growth factor by cationic self-assembling peptide/heparin hybrid hydrogel improves \&beta;-cell survival and function through modulating inflammatory response. Int J Nanomed. 2016;11:4875-90. https:// doi.org/10.2147/IJN.S108921.

94. Kim HS, Yoo HS. Matrix metalloproteinase-inspired suicidal treatments of diabetic ulcers with siRNA-decorated nanofibrous meshes. Gene Ther. 2013;20:378-85. https://doi.org/10.1038/gt.2012.49.

95. Uzunalli G, Tumtas Y, Delibasi T, Yasa O, Mercan S, Guler MO, et al. Improving pancreatic islet in vitro functionality and transplantation efficiency by using heparin mimetic peptide nanofiber gels. Acta Biomater. 2015;22:8-18. https://doi.org/10.1016/j.actbio.2015.04.032.

96. Choi JS, Choi SH, Yoo HS. Coaxial electrospun nanofibers for treatment of diabetic ulcers with binary release of multiple growth factors. J Mater Chem. 2011;21:5258. https://doi.org/10.1039/C0JM03706K.

97. Choi JS, Leong KW, Yoo HS. In vivo wound healing of diabetic ulcers using electrospun nanofibers immobilized with human epidermal growth factor (EGF). Biomaterials. 2008;29:587-96. https://doi.org/10. 1016/j.biomaterials.2007.10.012.

98. Lee C-H, Liu K-S, Cheng C-W, Chan E-C, Hung K-C, Hsieh M-J, et al. Codelivery of sustainable antimicrobial agents and platelet-derived growth factor via biodegradable nanofibers for repair of diabetic infectious wounds. ACS Infect Dis. 2020;6:2688-97. https://doi.org/10.1021/ acsinfecdis.0c00321.

99. Yang Y, Xia T, Zhi W, Wei L, Weng J, Zhang C, et al. Promotion of skin regeneration in diabetic rats by electrospun core-sheath fibers loaded with basic fibroblast growth factor. Biomaterials. 2011;32:4243-54. https://doi.org/10.1016/j.biomaterials.2011.02.042.

100. Zheng Z, Liu Y, Huang W, Mo Y, Lan Y, Guo R, et al. Neurotensin-loaded PLGA/CNC composite nanofiber membranes accelerate diabetic wound healing. Artif Cells Nanomed Biotechnol. 2018;46:493-501. https://doi.org/10.1080/21691401.2018.1460372.

101. Lai H-J, Kuan C-H, Wu H-C, Tsai J-C, Chen T-M, Hsieh D-J, et al. Tailored design of electrospun composite nanofibers with staged release of multiple angiogenic growth factors for chronic wound healing. Acta Biomater. 2014;10:4156-66. https://doi.org/10.1016/j.actbio.2014.05. 001.

102. Barati $G$, Rahmani A, Nadri S. In vitro differentiation of conjunctiva mesenchymal stem cells into insulin producing cells on natural and synthetic electrospun scaffolds. Biologicals. 2019;62:33-8. https://doi. org/10.1016/j.biologicals.2019.10.004.

103. Augustine R, Hasan A, Dalvi YB, Rehman SRU, Varghese R, Unni RN, et al. Growth factor loaded in situ photocrosslinkable poly(3-hydroxybutyrate-co-3-hydroxyvalerate)/gelatin methacryloyl hybrid patch for diabetic wound healing. Mater Sci Eng C. 2021;118: 111519. https:// doi.org/10.1016/j.msec.2020.111519.

104. Stendahl JC, Kaufman DB, Stupp SI. Extracellular matrix in pancreatic islets: relevance to scaffold design and transplantation. Cell Transplant. 2009;18:1-12. https://doi.org/10.3727/096368909788237195.

105. Liao S, Huang S, Xi T, Wu M, Zou Y, Li L, et al. Advances in polymeric biomaterial scaffolds for islet transplantation. J Biomed Eng. 2017:490511. https://doi.org/10.3969/j.iasn.0258-8021.2017.04.014.

106. Rickels MR, Robertson RP. Pancreatic islet transplantation in humans: recent progress and future directions. Endocr Rev. 2019;40:631-68. https://doi.org/10.1210/er.2018-00154.

107. Ali KF, Hatipoglu B. Pancreatic islet cell transplantation: graft stability and metabolic outcomes. OBM Transplant 2020;4:1-9. https://doi.org/ 10.21926/obm.transplant.2003115.

108. Gálisová A, Fábryová E, Sticová E, Kosinová L, Jirátová M, Herynek V, et al. The optimal timing for pancreatic islet transplantation into subcutaneous scaffolds assessed by multimodal imaging. Contrast Media Mol Imaging. 2017;2017:1-13. https://doi.org/10.1155/2017/5418495.

109. Tremmel DM, Odorico JS. Rebuilding a better home for transplanted islets. Organogenesis. 2018;14:163-8. https://doi.org/10.1080/15476 278.2018.1517509.

110. Khan S, Sur S, Newcomb CJ, Appelt EA, Stupp SI. Self-assembling glucagon-like peptide 1-mimetic peptide amphiphiles for enhanced activity and proliferation of insulin-secreting cells. Acta Biomater. 2012;8:1685-92. https://doi.org/10.1016/j.actbio.2012.01.036.

111. Zhu Y, Wang D, Yao X, Wang M, Zhao Y, LuY, et al. Biomimetic hybrid scaffold of electrospun silk fibroin and pancreatic decellularized extracellular matrix for islet survival. J Biomater Sci Polym Ed. 2021;32:15165. https://doi.org/10.1080/09205063.2020.1818018.

112. Ruhela A, Kasinathan GN, Rath SN, Sasikala M, Sharma CS. Electrospun freestanding hydrophobic fabric as a potential polymer semi-permeable membrane for islet encapsulation. Mater Sci Eng C. 2021;118: 111409. https://doi.org/10.1016/j.msec.2020.111409.

113. Yang B, Cao G, Cai K, Wang G, Li P, Zheng L, et al. VEGF-modified PVA/ silicone nanofibers enhance islet function transplanted in subcutaneous site followed by device-less procedure. Int J Nanomed. 2020;15:587-99. https://doi.org/10.2147/IJN.S232224.

114. Sojoodi M, Farrokhi A, Moradmand A, Baharvand H. Enhanced maintenance of rat islets of Langerhans on laminin-coated electrospun nanofibrillar matrix in vitro. Cell Biol Int. 2013;37:370-9. https://doi.org/ 10.1002/cbin. 10045.

115. Chen W, Zhang Q, Luk BT, Fang RH, Liu Y, Gao W, et al. Coating nanofiber scaffolds with beta cell membrane to promote cell proliferation and function. Nanoscale. 2016;8:10364-70. https://doi.org/10. 1039/C6NR00535G.

116. Mansour RN, Barati G, Soleimani M, Ghoraeian P, Nouri Aleagha M, Kehtari $\mathrm{M}$, et al. Generation of high-yield insulin producing cells from human-induced pluripotent stem cells on polyethersulfone nanofibrous scaffold. Artif Cells Nanomed Biotechnol. 2018;46:733-9. https:// doi.org/10.1080/21691401.2018.1434663.

117. Mansour RN, Soleimanifar F, Abazari MF, Torabinejad S, Ardeshirylajimi A, Ghoraeian P, et al. Collagen coated electrospun polyethersulfon nanofibers improved insulin producing cells differentiation potential of human induced pluripotent stem cells. Artif Cells Nanomed Biotechnol. 2018;46:S734-9. https://doi.org/10.1080/21691401.2018. 1508031. 
118. Enderami SE, Kehtari M, Abazari MF, Ghoraeian P, Nouri Aleagha M, Soleimanifar F, et al. Generation of insulin-producing cells from human induced pluripotent stem cells on PLLA/PVA nanofiber scaffold. Artif Cells Nanomed Biotechnol. 2018:46:1062-9. https://doi.org/10.1080/ 21691401.2018.1443466.

119. Ojaghi M, Soleimanifar F, Kazemi A, Ghollasi M, Soleimani M, Nasoohi $\mathrm{N}$, et al. Electrospun poly-L-lactic acid/polyvinyl alcohol nanofibers improved insulin-producing cell differentiation potential of human adipose-derived mesenchymal stem cells. J Cell Biochem. 2019;120:9917-26. https://doi.org/10.1002/jcb.28274.

120. Hoveizi E, Tavakol S. Therapeutic potential of human mesenchymal stem cells derived beta cell precursors on a nanofibrous scaffold: an approach to treat diabetes mellitus. J Cell Physiol. 2019;234:10196-204. https://doi.org/10.1002/jcp.27689.

121. Hoveizi E, Mohammadi T. Differentiation of endometrial stem cells into insulin-producing cells using signaling molecules and zinc oxide nanoparticles, and three-dimensional culture on nanofibrous scaffolds. J Mater Sci Mater Med. 2019;30:101. https://doi.org/10.1007/ s10856-019-6301-3.

122. Enderami SE, Ahmadi SF, Mansour RN, Abediankenari S, Ranjbaran H, Mossahebi-Mohammadi M, et al. Electrospun silk nanofibers improve differentiation potential of human induced pluripotent stem cells to insulin producing cells. Mater Sci Eng. 2020;108: 110398. https://doi. org/10.1016/j.msec.2019.110398.

123. Hosseini M, Dadashi-Noshahr K, Islami M, Saburi E, Nikpoor AR, Mellati A, et al. A novel silk/PES hybrid nanofibrous scaffold promotes the in vitro proliferation and differentiation of adipose-derived mesenchymal stem cells into insulin producing cells. Polym Adv Technol. 2020;31:1857-64. https://doi.org/10.1002/pat.4912.

124. Abazari MF, Zare Karizi S, Hajati-Birgani N, Norouzi S, Khazeni Z, Hashemi J, et al. PHBV nanofibers promotes insulin-producing cells differentiation of human induced pluripotent stem cells. Gene. 2021;768: 145333. https://doi.org/10.1016/j.gene.2020.145333.

125. Enderami SE, Soleimani M, Mortazavi Y, Nadri S, Salimi A. Generation of insulin-producing cells from human adipose-derived mesenchymal stem cells on PVA scaffold by optimized differentiation protocol. J Cell Physiol. 2018;233:4327-37. https://doi.org/10.1002/jcp.26266.

126. Abazari MF, Soleimanifar F, Nouri Aleagha M, Torabinejad S, Nasiri N, Khamisipour G, et al. PCL/PVA nanofibrous scaffold improve insulinproducing cells generation from human induced pluripotent stem cells. Gene. 2018;671:50-7. https://doi.org/10.1016/j.gene.2018.05.115.

127. Gooraninejad S, Hoveizi E, Hushmandi K, Gooraninejad S, Tabatabaei SRF. Small molecule differentiate PDX1-expressing cells derived from human endometrial stem cells on PAN electrospun nanofibrous scaffold: applications for the treatment of diabetes in rat. Mol Neurobiol. 2020;57:3969-78. https://doi.org/10.1007/s12035-020-02007-z.

128. Zafari F, Shirian S, Sadeghi M, Teimourian S, Bakhtiyari M. CD93 hematopoietic stem cells improve diabetic wound healing by VEGF activation and downregulation of DAPK-1. J Cell Physiol. 2020;235:2366-76. https://doi.org/10.1002/jcp.29142.

129. Chen S, Wang H, Su Y, John JV, McCarthy A, Wong SL, et al. Mesenchymal stem cell-laden, personalized 3D scaffolds with controlled structure and fiber alignment promote diabetic wound healing. Acta Biomater. 2020;108:153-67. https://doi.org/10.1016/j.actbio.2020.03. 035.

130. Chu J, Shi P, Yan W, Fu J, Yang Z, He C, et al. PEGylated graphene oxidemediated quercetin-modified collagen hybrid scaffold for enhancement of MSCs differentiation potential and diabetic wound healing. Nanoscale. 2018;10:9547-60. https://doi.org/10.1039/C8NR02538J.

131. Manoukian OS, Ahmad A, Marin C, James R, Mazzocca AD, Kumbar SG. Bioactive nanofiber dressings for wound healing. In: Wound healing biomaterials. Elsevier 2016:451-81. https://doi.org/10.1016/B978-178242-456-7.00022-2

132. Rieger KA, Birch NP, Schiffman JD. Designing electrospun nanofiber mats to promote wound healing —a review. J Mater Chem BT. 2013;1:4531. https://doi.org/10.1039/C3TB20795A.

133. Liu S, Zhang Q, Yu J, Shao N, Lu H, Guo J, et al. Absorbable thioether grafted hyaluronic acid nanofibrous hydrogel for synergistic modulation of inflammation microenvironment to accelerate chronic diabetic wound healing. Adv Healthc Mater John. 2020;9:2000198. https://doi. org/10.1002/adhm.202000198.
134. Rezvanian M, Ng S-F, Alavi T, Ahmad W. In-vivo evaluation of Alginate-Pectin hydrogel film loaded with Simvastatin for diabetic wound healing in Streptozotocin-induced diabetic rats. Int J Biol Macromol. 2021;171:308-19. https://doi.org/10.1016/j.ijbiomac. 2020.12.221.

135. Spampinato SF, Caruso GI, De Pasquale R, Sortino MA, Merlo S. The treatment of impaired wound healing in diabetes: looking among old drugs. Pharmaceuticals. 2020;13:60. https://doi.org/10.3390/ ph13040060.

136. Masri S, Fauzi MB. Current insight of printability quality improvement strategies in natural-based bioinks for skin regeneration and wound healing. Polymers. 2021;13:1011. https://doi.org/10.3390/ polym13071011.

137. Chen T-Y, Wen T-K, Dai N-T, Hsu S. Cryogel/hydrogel biomaterials and acupuncture combined to promote diabetic skin wound healing through immunomodulation. Biomaterials. 2021;269: 120608. https://doi.org/10.1016/j.biomaterials.2020.120608.

138. Xue M, Zhao R, March L, Jackson C. Dermal fibroblast heterogeneity and its contribution to the skin repair and regeneration. Adv Wound Care 2020:1287. https://doi.org/10.1089/wound.2020.1287.

139. Sena S, Sumeyra KN, Ulkugul G, Sema A, Betul K, Muge SB, et al. Controlled release of metformin hydrochloride from core-shell nanofibers with fish sarcoplasmic protein. Medicina (Kaunas). 2019;55:682. https://doi.org/10.3390/medicina55100682.

140. Yunus Basha R, Sampath Kumar TS, Selvaraj R, Doble M. Silver loaded nanofibrous curdlan mat for diabetic wound healing: an in vitro and in vivo study. Macromol Mater Eng. 2018;303:1800234. https://doi. org/10.1002/mame.201800234.

141. Chouhan D, Janani G, Chakraborty B, Nandi SK, Mandal BB. Functionalized PVA-silk blended nanofibrous mats promote diabetic wound healing via regulation of extracellular matrix and tissue remodelling. J Tissue Eng Regen Med. 2018;12:1559-70. https://doi.org/10.1002/ term.2581.

142. Merrell JG, McLaughlin SW, Tie L, Laurencin CT, Chen AF, Nair LS. Curcumin-loaded poly( $\varepsilon$-caprolactone) nanofibres: diabetic wound dressing with anti-oxidant and anti-inflammatory properties. Clin Exp Pharmacol Physiol. 2009;36:1149-56. https://doi.org/10.1111/j. 1440-1681.2009.05216.x.

143. Ranjbar-Mohammadi M, Rabbani S, Bahrami SH, Joghataei MT, Moayer F. Antibacterial performance and in vivo diabetic wound healing of curcumin loaded gum tragacanth/poly( $\varepsilon$-caprolactone) electrospun nanofibers. Mater Sci Eng C. 2016;69:1183-91. https:// doi.org/10.1016/j.msec.2016.08.032.

144. Guleken Z, Depciuch J, Ege H, Ilbay G, Kalkandelen C, Ozbeyli D, et al. Spectrochemical and biochemical assay comparison study of the healing effect of the Aloe vera and Hypericum perforatum loaded nanofiber dressings on diabetic wound. Spectrochim Acta A Mol Biomol Spectrosc. 2021;254: 119639. https://doi.org/10.1016/j.saa. 2021.119639

145. Pinzón-García AD, Cassini-Vieira P, Ribeiro CC, de Matos Jensen CE, Barcelos LS, Cortes ME, et al. Efficient cutaneous wound healing using bixin-loaded PCL nanofibers in diabetic mice. J Biomed Mater Res Part B Appl Biomater. 2017;105:1938-49. https://doi.org/10.1002/jbm.b. 33724.

146. Zehra M, Zubairi W, Hasan A, Butt H, Ramzan A, Azam M, et al. Oxygen generating polymeric nano fibers that stimulate angiogenesis and show efficient wound healing in a diabetic wound model. Int J Nanomed. 2020;15:3511-22. https://doi.org/10.2147/JJN.S248911.

147. Cam ME, Ertas B, Alenezi H, Hazar-Yavuz AN, Cesur S, Ozcan GS, et al. Accelerated diabetic wound healing by topical application of combination oral antidiabetic agents-loaded nanofibrous scaffolds: an in vitro and in vivo evaluation study. Mater Sci Eng. 2021;119: 111586. https://doi.org/10.1016/j.msec.2020.111586.

148. Yu B, He C, Wang W, Ren Y, Yang J, Guo S, et al. Asymmetric wettable composite wound dressing prepared by electrospinning with bioinspired micropatterning enhances diabetic wound healing. ACS Appl Bio Mater. 2020;3:5383-94. https://doi.org/10.1021/acsabm.0c00695.

149. Khan AuR, Huang K, Khalaji MS, Yu F, Xie X, Zhu T, et al. Multifunctional bioactive core-shell electrospun membrane capable to terminate inflammatory cycle and promote angiogenesis in diabetic wound. 
Bioact Mater. 2021;6:2783-800. https://doi.org/10.1016/j.bioactmat. 2021.01.040.

150. Lv F, Wang J, Xu P, Han Y, Ma H, Xu H, et al. A conducive bioceramic/ polymer composite biomaterial for diabetic wound healing. Acta Biomater. 2017;60:128-43. https://doi.org/10.1016/j.actbio.2017.07. 020.

151. Gao W, Sun L, Fu X, Lin Z, Xie W, Zhang W, et al. Enhanced diabetic wound healing by electrospun core-sheath fibers loaded with dimethyloxalylglycine. J Mater Chem B. 2018;6:277-88. https://doi. org/10.1039/C7TB02342A.

152. Ranjbar Mohammadi M, Kargozar S, Bahrami SH, Rabbani S. An excellent nanofibrous matrix based on gum tragacanth-poly ( $\mathcal{E}$-caprolactone)-poly (vinyl alcohol) for application in diabetic wound healing. Polym Degrad Stab. 2020;174: 109105. https://doi. org/10.1016/j.polymdegradstab.2020.109105.

153. Gholipour-Kanani A, Bahrami SH, Rabbani S. Effect of novel blend nanofibrous scaffolds on diabetic wounds healing. IET Nanobiotechnol. 2016;10:1-7. https://doi.org/10.1049/iet-nbt.2014.0066.

154. Chen X, Zhou W, Zha K, Liu G, Yang S, Ye S, et al. Treatment of chronic ulcer in diabetic rats with self assembling nanofiber gel encapsulated-polydeoxyribonucleotide. Am J Transl Res. 2016;8:3067-76. https://www.ncbi.nlm.nih.gov/pmc/articles/PMC49 69443/

155. Sami DG, Abdellatif A, Azzazy HME. Turmeric/oregano formulations for treatment of diabetic ulcer wounds. Drug Dev Ind Pharm. 2020;46:1613-21. https://doi.org/10.1080/03639045.2020.1811305.

156. Chao F-C, Wu M-H, Chen L-C, Lin H-L, Liu D-Z, Ho H-O, et al. Preparation and characterization of chemically TEMPO-oxidized and mechanically disintegrated sacchachitin nanofibers (SCNF) for enhanced diabetic wound healing. Carbohydr Polym. 2020;229: 115507. https://doi.org/10.1016/j.carbpol.2019.115507.

157. Grip J, Engstad RE, Skjæveland I, Škalko-Basnet N, Isaksson J, Basnet $P$, et al. Beta-glucan-loaded nanofiber dressing improves wound healing in diabetic mice. Eur J Pharm Sci. 2018;121:269-80. https:// doi.org/10.1016/j.ejps.2018.05.031.

158. Chogan F, Mirmajidi T, Rezayan AH, Sharifi AM, Ghahary A, Nourmohammadi J, et al. Design, fabrication, and optimization of a dual function three-layer scaffold for controlled release of metformin hydrochloride to alleviate fibrosis and accelerate wound healing. Acta Biomater. 2020;113:144-63. https://doi.org/10.1016/j.actbio. 2020.06.031.

159. Ahmadi Majd S, Rabbani Khorasgani M, Moshtaghian SJ, Talebi A Khezri M. Application of Chitosan/PVA Nano fiber as a potential wound dressing for streptozotocin-induced diabetic rats. Int J Biol Macromol. 2016;92:1162-8. https://doi.org/10.1016/j.ijbiomac.2016. 06.035 .

160. Ahmed R, Tariq M, Ali I, Asghar R, Noorunnisa Khanam P, Augustine $R$, et al. Novel electrospun chitosan/polyvinyl alcohol/zinc oxide nanofibrous mats with antibacterial and antioxidant properties for diabetic wound healing. Int J Biol Macromol. 2018;120:385-93. https://doi.org/10.1016/j.ijbiomac.2018.08.057.

161. Yang B-Y, Hu C-H, Huang W-C, Ho C-Y, Yao C-H, Huang C-H. Effects of bilayer nanofibrous scaffolds containing curcumin/lithospermi radix extract on wound healing in streptozotocin-induced diabetic rats. Polymers. 2019;11:1745. https://doi.org/10.3390/polym11111745.

162. Chen Q, Wu J, Liu Y, Li Y, Zhang C, Qi W, et al. Electrospun chitosan/ PVA/bioglass Nanofibrous membrane with spatially designed structure for accelerating chronic wound healing. Mater Sci Eng C. 2019;105: 110083. https://doi.org/10.1016/j.msec.2019.110083.

163. Cam ME, Crabbe-Mann M, Alenezi H, Hazar-Yavuz AN, Ertas B, Ekentok $C$, et al. The comparision of glybenclamide and metforminloaded bacterial cellulose/gelatin nanofibres produced by a portable electrohydrodynamic gun for diabetic wound healing. Eur Polym J. 2020;134: 109844. https://doi.org/10.1016/j.eurpolymj.2020. 109844.

164. Liu F, Li X, Wang L, Yan X, Ma D, Liu Z, et al. Sesamol incorporated cellulose acetate-zein composite nanofiber membrane: an efficient strategy to accelerate diabetic wound healing. Int J Biol Macromol. 2020;149:627-38. https://doi.org/10.1016/j.ijbiomac.2020.01.277.

165. Almasian A, Najafi F, Eftekhari M, Ardekani MRS, Sharifzadeh M, Khanavi M. Polyurethane/carboxymethylcellulose nanofibers containing
Malva sylvestris extract for healing diabetic wounds: preparation, characterization, in vitro and in vivo studies. Mater Sci Eng C. 2020;114: 111039. https://doi.org/10.1016/j.msec.2020.111039.

166. Li J, Lv F, Li J, Li Y, Gao J, Luo J, et al. Cobalt-based metal-organic framework as a dual cooperative controllable release system for accelerating diabetic wound healing. Nano Res. 2020;13:2268-79. https://doi.org/10.1007/s12274-020-2846-1.

167. El-Lakany SA, Kamoun EA, Abd-Elhamid Al, Aly RG, Samy WM, Elgindy NA. Graphene oxide crosslinked-zein nanofibrous scaffolds for prominent $\mathrm{Cu}$-adsorption as tissue regeneration promoters in diabetic rats: nanofibers optimization and in vivo assessment. Int J Pharm. 2020;590: 119919. https://doi.org/10.1016/j.jpharm.2020. 119919.

168. Zhang P, Li Y, Tang Y, Shen H, Li J, Yi Z, et al. Copper-based metalorganic framework as a controllable nitric oxide-releasing vehicle for enhanced diabetic wound healing. ACS Appl Mater Interfaces. 2020;12:18319-31. https://doi.org/10.1021/acsami.0c01792.

169. Jiang Y, Han Y, Wang J, Lv F, Yi Z, Ke Q, et al. Space-oriented nanofibrous scaffold with silicon-doped amorphous calcium phosphate nanocoating for diabetic wound healing. ACS Appl Bio Mater. 2019;2:787-95. https://doi.org/10.1021/acsabm.8b00657.

170. Lee C-H, Chang S-H, Chen W-J, Hung K-C, Lin Y-H, Liu S-J, et al. Augmentation of diabetic wound healing and enhancement of collagen content using nanofibrous glucophage-loaded collagen/PLGA scaffold membranes. J Colloid Interface Sci. 2015;439:88-97. https://doi. org/10.1016/j.jcis.2014.10.028.

171. Lee C-H, Hsieh M-J, Chang S-H, Lin Y-H, Liu S-J, Lin T-Y, et al. Enhancement of diabetic wound repair using biodegradable nanofibrous metformin-eluting membranes: in vitro and in vivo. ACS Appl Mater Interfaces. 2014;6:3979-86. https://doi.org/10.1021/am405329g.

172. Liao HT, Lai Y-T, Kuo C-Y, Chen J-P. A bioactive multi-functional heparin-grafted aligned poly(lactide-co-glycolide)/curcumin nanofiber membrane to accelerate diabetic wound healing. Mater Sci Eng C. 2021;120: 111689. https://doi.org/10.1016/j.msec.2020.111689.

173. Yu M, Huang J, Zhu T, Lu J, Liu J, Li X, et al. Liraglutide-loaded PLGA/ gelatin electrospun nanofibrous mats promote angiogenesis to accelerate diabetic wound healing via the modulation of miR29b-3p. Biomater Sci. 2020;8:4225-38. https://doi.org/10.1039/ D0BM00442A.

174. Pietramaggiori G, Yang H-J, Scherer SS, Kaipainen A, Chan RK, Alperovich $\mathrm{M}$, et al. Effects of poly-N-acetyl glucosamine (pGlcNAc) patch on wound healing in $\mathrm{db} / \mathrm{db}$ mouse. J Trauma Inj Infect Crit Care. 2008;64:803-8. https://doi.org/10.1097/01.ta.0000244382.13937.a8.

175. Kanji S, Das M, Joseph M, Aggarwal R, Sharma SM, Ostrowski M, et al. Nanofiber-expanded human CD34+ cells heal cutaneous wounds in streptozotocin-induced diabetic mice. Sci Rep. 2019;9:8415. https:// doi.org/10.1038/s41598-019-44932-7.

176. Han Y, Jiang Y, Li Y, Wang M, Fan T, Liu M, et al. An aligned porous electrospun fibrous scaffold with embedded asiatic acid for accelerating diabetic wound healing. J Mater Chem B. 2019;7:6125-38. https://doi.org/10.1039/C9TB01327.

177. Chouhan D, Das P, Thatikonda N, Nandi SK, Hedhammar M, Mandal BB. Silkworm silk matrices coated with functionalized spider silk accelerate healing of diabetic wounds. ACS Biomater Sci Eng. 2019;5:3537-48. https://doi.org/10.1021/acsbiomaterials.9b00514.

178. Elshazly N, Khalil A, Saad M, Patruno M, Chakraborty J, Marei M. Efficacy of bioactive glass nanofibers tested for oral mucosal regeneration in rabbits with induced diabetes. Materials. 2020;13:2603.

179. Cui S, Sun X, Li K, Gou D, Zhou Y, Hu J, et al. Polylactide nanofibers delivering doxycycline for chronic wound treatment. Mater Sci Eng C. 2019;104: 109745. https://doi.org/10.1016/j.msec.2019.109745.

180. Shahverdi S, Hajimiri M, Esfandiari MA, Larijani B, Atyabi F, Rajabiani $\mathrm{A}$, et al. Fabrication and structure analysis of poly(lactide-co-glycolic acid)/silk fibroin hybrid scaffold for wound dressing applications. Int J Pharm. 2014;473:345-55. https://doi.org/10.1016/j.ijpharm.2014.07. 021.

181. Modgill V, Garg T, Rath AKG. Transmucosal delivery of linagliptin for the treatment of type-2 diabetes mellitus by ultra-thin nanofibers. Curr Drug Deliv. 2015;12:323-32. https://doi.org/10.2174/15672 01811666141117144332. 
182. Thakkar S, More N, Sharma D, Kapusetti G, Kalia K, Misra M. Fast dissolving electrospun polymeric films of anti-diabetic drug repaglinide: formulation and evaluation. Drug Dev Ind Pharm. 2019:45:192130. https://doi.org/10.1080/03639045.2019.1680994.

183. Heydari-Majd M, Rezaeinia H, Shadan MR, Ghorani B, Tucker N. Enrichment of zein nanofibre assemblies for therapeutic delivery of Barije (Ferula gummosa Boiss) essential oil. J Drug Deliv Sci Technol. 2019;54: 101290. https://doi.org/10.1016/j.jddst.2019.101290.

184. Lee $\mathrm{C}-\mathrm{H}$, Hsieh M-J, Chang S-H, Hung K-C, Wang C-J, Hsu M-Y, et al. Nanofibrous vildagliptin-eluting stents enhance re-endothelialization and reduce neointimal formation in diabetes: in vitro and in vivo. Int J Nanomed. 2019;14:7503-13. https://doi.org/10.2147/ IJN.S237537.

185. Advanced Wound Care Market Size and Regional Forecast 2025. https://www.gminsights.com/industry-analysis/advan ced-wound-care-market.

\section{Publisher's Note}

Springer Nature remains neutral with regard to jurisdictional claims in published maps and institutional affiliations.
Ready to submit your research? Choose BMC and benefit from:

- fast, convenient online submission

- thorough peer review by experienced researchers in your field

- rapid publication on acceptance

- support for research data, including large and complex data types

- gold Open Access which fosters wider collaboration and increased citations

- maximum visibility for your research: over 100M website views per year

At BMC, research is always in progress.

Learn more biomedcentral.com/submissions 